\title{
Petrografia e Química Mineral dos Diques Máficos da Região Crixás-Goiás, Estado de Goiás
}

\author{
Paulo César Corrêa da Costa (pccorrea@usp.br) e Vicente Antonio Vitório Girardi \\ Departamento de Mineralogia e Geotectônica - Instituto de Geociências - USP \\ R. do Lago 562, CEP 05508-080, São Paulo, SP, BRA
}

Palavras-chave: diques máficos, quimismo mineral, Estado de Goiás.

\section{RESUMO}

No Bloco Arqueano de Goiás (Centro-Oeste do Brasil) ocorrem diques máficos paleoproterozóicos orientados preferencialmente segundo NE e NW. Em função dos aspectos petrográficos foram classificados em: diabásio, metabasito e anfibolito. Sob o ponto de vista químico tratam-se de toleítos, situando-se a grande maioria deles no campo do basalto, sendo que alguns, principalmente o diabásio, situam-se no campo do andesito basáltico. Diabásio, metabasito e, pelo menos parte dos anfibolitos parece ser cogenética. Os diques de diabásio e metabasito contêm piroxênios de composições ricas (augita) e pobres (enstatita e pigeonita) em cálcio. Nesses diques verifica-se que, tanto para os piroxênios ricos quanto pobres em cálcio, os conteúdos de wollastonita (Wo) decrescem dos núcleos para as bordas dos grãos acompanhados de um aumento dos teores de ferrossilita (Fs). Nos piroxênios pobres em cálcio, há um fraco incremento em Wo, e moderado enriquecimento em Fs. As análises de núcleos e bordas dos grãos de plagioclásio mostraram composições que variam de labradorita a bytownita no diabásio e metabasito e andesina a oligoclásio nos anfibolitos. As temperaturas de cristalização obtidas no diabásio e metabasito, segundo vários geotermômetros, indicam os mesmos intervalos de temperatura, quer utilizando-se os piroxênios, cuja variação média vai de $1100^{\circ} \mathrm{C}$ a $1200^{\circ} \mathrm{C}$, quer usando-se plagioclásio, cuja variação média situa-se em $1100^{\circ} \mathrm{C}$. Existem dois tipos de anfibólios cálcicos: primários e secundários. Suas composições são muito variadas, principalmente no que concerne aos elementos de $\mathrm{Mg}$ e Fe. Análises químicas de opacos revelaram a presença de magnetita e ilmenita.

Keywords: mafic dykes, mineral chemistry, Goiás state.

\section{ABSTRACT}

Paleoproterozoic mafic dikes intrude Archean rocks of the Goiás Block along two main trends, NE and NW. Based on petrographic features they are classified in three groups: diabase, metabasite and amphibolite. Chemical analyses display tholeiitic affinity and permit the great majority of rocks to be classified as basalt. Some samples, mainly diabase, are basaltic andesites. Diabase, metabasite, and at least part of the amphibolites seem to be cogenetic. Diabase and metabasite contain Carich (augite) and Ca-poor pyroxenes (enstatite and pigeonite). In both types the wollastonite content (Wo) decreases and the ferrosilite component (Fs) increases from core to rim of the pyroxenes. This compositional variation is less pronounced in the $\mathrm{Ca}$-poor pyroxenes. Cores and rims of plagioclases of diabase and metabasite vary from labradorite to bytownite. In the amphibolites the plagioclase ranges from oligoclase to andesine. Several geothermometers indicate similar crystallization temperatures for diabase and metabasite. Data from pyroxene and plagioclase point out average values of $1100^{\circ} \mathrm{C}-1200^{\circ} \mathrm{C}$ and $1100^{\circ} \mathrm{C}$ respectively. Igneous and secondary amphiboles (derived from pyroxenes) exhibit a large compositional range, mainly due to variable contents of $\mathrm{FeO}$ and $\mathrm{MgO}$. Chemical analyses of opaque minerals identified magnetite and ilmenite. 


\section{INTRODUÇÃO}

O estudo dos enxames de diques máficos tem sido abordado por vários autores, pois tais estudos fornecem informações relevantes sobre processos mantélicos e geodinâmicos (e. g. Condie et al., 1987; Teixeira, 1990; Bossi et al., 1993; Bellieni et al., 1995; Mazzucchelli et al., 1995; Corrêa Gomes et al., 1996; Pinese, 1997; Mazzucchelli et al., 2000; Menezes Leal et al., 2000; Iacumin et al., 2001, 2003).

Os diques máficos de Goiás, na região centro-oeste do Brasil, já foram objeto de alguns estudos (e.g. Kuyumjian, 1991, 1998; Girardi et al., 1992; Tomazzoli, 1997; Corrêa da Costa et al., 2002; Corrêa da Costa et al., 2003). Este trabalho tem como objetivo o estudo petrográfico e principalmente o quimismo mineral e a termometria desses corpos.

\section{CONTEXTO GEOLÓGICO}

A área de trabalho está inserida no Bloco Arqueano de Goiás. Esse segmento crustal corresponde à porção central da Província Tocantins segundo Almeida et al. (1977; Figura 1). A Província Tocantins corresponde à região afetada pela colisão dos crátons Amazônico, a oeste, e São Francisco, a leste, durante o Ciclo Brasiliano (Winge, 2000).

Em geral, as principais unidades do Bloco Arqueano de Goiás são os terrenos arqueanos granito-greenstone de Goiás, Crixás, Guarinos, Pilar de Goiás e Hidrolina, acrescidos de terrenos ortognáissicos de idade paleoproterozóica, cobertos por metassedimentos (e. g. Grupo Serra da Mesa), sequiências metavulcano-sedimentares e ainda os complexos estratiformes máfico-ultramáficos Barro Alto,

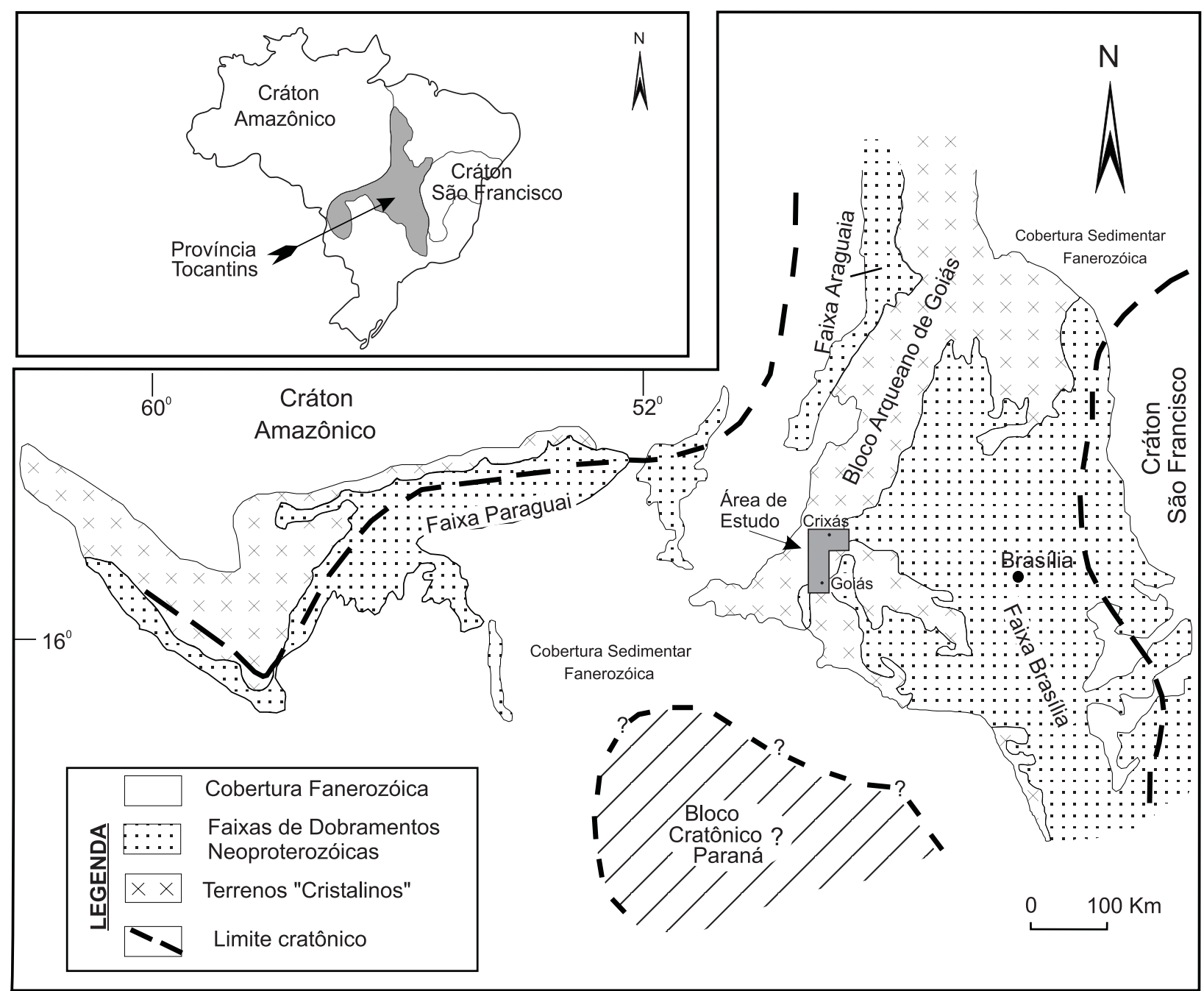

Figura 1. Esboço geológico da Província Tocantins, mostrando a localização da área estudada, o Bloco Arqueano de Goiás e as Faixas de Dobramentos Brasília e Paraguai-Araguaia (Modificado de Pimentel et al., 1997). 
Niquelândia e Cana Brava (Girardi et al., 1981, 1986; Correia et al., 1997).

Na porção norte do Bloco Arqueano de Goiás, os gnaisse-granodioríticos correspondem ao Complexo Anta, enquanto que, os gnaisse-tonalíticos equivalem ao Complexo Caiamar de acordo com Jost et al. (1994) e Queiroz (2000). As rochas granito-gnáissicas da porção central e sul do Bloco Arqueano de Goiás fazem parte dos Complexos Caiçara e Uvá, respectivamente.

De modo geral, nos terrenos granito-gnáissicos ocorrem diques máficos, que se estendem linearmente, algumas vezes, por dezenas de quilômetros e têm espessuras que variam de poucos metros até uma centena de metros.

Os diques máficos distribuem-se por toda região investigada, apresentando maior densidade de ocorrência na sua porção meridional, entre as cidades de Goiás e Morro Agudo de Goiás e na porção setentrional, entre as cidades de Crixás e Auriverde. Esses diques cortam os terrenos granito-gnáissicos com idades compreendidas entre 3067 a $2670 \mathrm{Ma}$ (idades obtidas por Hasui e Almeida, 1970; Tassinari e Montalvão, 1980; Vargas, 1992; Tomazzoli, 1992 e Pimentel et al., 2003).

\section{ASPECTOS GEOLÓGICOS E PETROGRÁFICOS}

Análises ${ }^{39} \mathrm{Ar}-{ }^{40} \mathrm{Ar}$ e $\mathrm{Rb} / \mathrm{Sr}$ (e. g. Corrêa da Costa et al., 2003) indicam idade de cerca de 2,4 Ga para a cristalização dos diques de diabásio.

Os diques máficos afloram na forma de blocos arredondados, distribuindo-se preferencialmente segundo as direções de intrusão N10-30E, N30-40E, N40-60E e NW. Os diques de diabásio e metabasito têm direções preferenciais que variam de N10E a N40E, enquanto os diques de anfibolito apresentam direções tanto NE como NW.

Em geral, esses diques são verticais a subverticais e possuem espessuras que variam de poucos metros $(10-15 \mathrm{~m})$, podendo atingir até $100 \mathrm{~m}$ de espessura com vários quilômetros de comprimento.

Os diques de anfibolito são os que apresentam as menores espessuras. Em média variam aproximadamente de 10 a $20 \mathrm{~m}$. Os diques de diabásio por sua vez, são um pouco mais espessos que os diques de anfibolitos, com valores médios de 40 a $50 \mathrm{~m}$. Os diques de metabasito são os mais expressivos e podem apresentar espessuras de aproximadamente até $100 \mathrm{~m}$ e, também, são os que apresentam as maiores extensões.

Os dados petrográficos, que incluem estruturas, texturas, composição mineralógica, e transformações hidrotermais/metamórficas permitiram classificar as rochas máficas da região investigada em três grupos distintos: Diabásio, Metabasito e Anfibolito.

\section{Diabásio}

O diabásio representa cerca de $27 \%$ das rochas investigadas. São rochas faneríticas, com granulação variando de fina a média. Apresentam textura predominante subofítica e intergranular e subordinadamente ofítica. Com menor freqüência ocorre a textura porfirítica com fenocristais de piroxênio de aproximadamente 2,5 $\mathrm{mm}$ dispersos numa matriz fina de piroxênio e plagioclásio. Raramente observase estrutura vesicular com quartzo em matriz muito fina $(0,1 \mathrm{~mm})$. Intercrescimento micrográfico ou granofírico é freqüente.

Estas rochas são compostas essencialmente por plagioclásio e piroxênio (orto e clinopiroxênio) que juntos correspondem a aproximadamente 80 - $85 \%$ do volume total da amostra. Em menores proporções têm minerais acessórios como anfibólio primário ('́gneo), quartzo, biotita, minerais opacos, apatita, titanita, zircão e zoisita.

\section{Metabasito}

O metabasito constitui diques de ampla frequiência na região, e representa cerca de $34 \%$ das rochas estudadas. Seus constituintes mineralógicos essenciais são plagioclásio, anfibólio e subordinadamente piroxênio (orto e clinopiroxênio). Alguns anfibólios são primários, porém a grande maioria advém da transformação hidrotermal ou deutérica dos piroxênios. As texturas predominantes são as mesmas do diabásio, ou sejam ofítica e subofítica e mais raramente a porfirítica. Opacos, quartzo, apatita, biotita, zircão, titanita e epidoto são acessórios.

\section{Anfibolito}

À semelhança do diabásio e metabasito, este grupo tem sua distribuição geográfica abrangente e pode ser encontrado em toda a região investigada. Representa cerca de $39 \%$ das rochas investigadas. As direções predominantes são N10 - 20W para o anfibolito na região de Crixás e N40 60E para os existentes nas imediações de Goiás.

As rochas são foliadas e de granulação predominantemente fina. A foliação principal, geralmente é observada nas bordas dos diques, próxima do contato com a rocha encaixante, sendo paralela à direção de intrusão. Situação semelhante a esta, de diques que sofreram reativações por cisalhamento simples, também têm sido relatadas na literatura (e. g. Corrêa Gomes, 1989; Tarney, 1992; Menezes Leal et al., 1995; Bellieni et al., 1995 e Pinese, 1997).

A mineralogia é constituída essencialmente por anfibólio e plagioclásio que somados representam cerca de $90 \%$ do volume da rocha. Como minerais acessórios aparecem quartzo, minerais opacos, biotita, apatita, zircão, titanita e epidoto. 
As texturas são granoblástica e nematoblástica.

Cumpre salientar um aspecto textural e mineralógico de grande importância no que se refere à consangüinidade das três litologias. Em alguns diques mais espessos notou-se no centro diabásio com texturas ofíticas e subofíticas. Em se afastando do centro as texturas permanecem, havendo, porém, enriquecimento de anfibólio secundário. Nas bordas estruturas foliadas e texturas nematoblásticas caracterizam as rochas. Tais feições sugerem que, pelo menos parte dos anfibolitos, é cogenética e contemporânea a diabásios e metabasitos. No que se refere à classificação dessas rochas por critérios químicos foram utilizadas análises químicas de elementos maiores. Os dados químicos completos das rochas encontram-se em Corrêa da Costa (2003) e mostram claramente a afinidade toleítica de todos os litotipos (Figura 2). Nesse gráfico é possível também notar dois grupos de rochas: um mais rico em $\mathrm{FeO}$, correspondendo a amostras com mais de $1,5 \%$ de $\mathrm{TiO}_{2}$, e outro mais rico em $\mathrm{MgO}$ com menos de $1,5 \%$ de $\mathrm{TiO}_{2}$.

No diagrama de Le Bas et al. (1986) observa-se que os litotipos são predominantemente basalto, situando-se algumas amostras, principalmente diabásio, no campo do andesito basáltico (Figura 3). Nota-se também uma separação entre os grupos com $\mathrm{TiO}_{2}$ abaixo e acima de $1,5 \%$, sendo estes mais enriquecidos em álcalis.

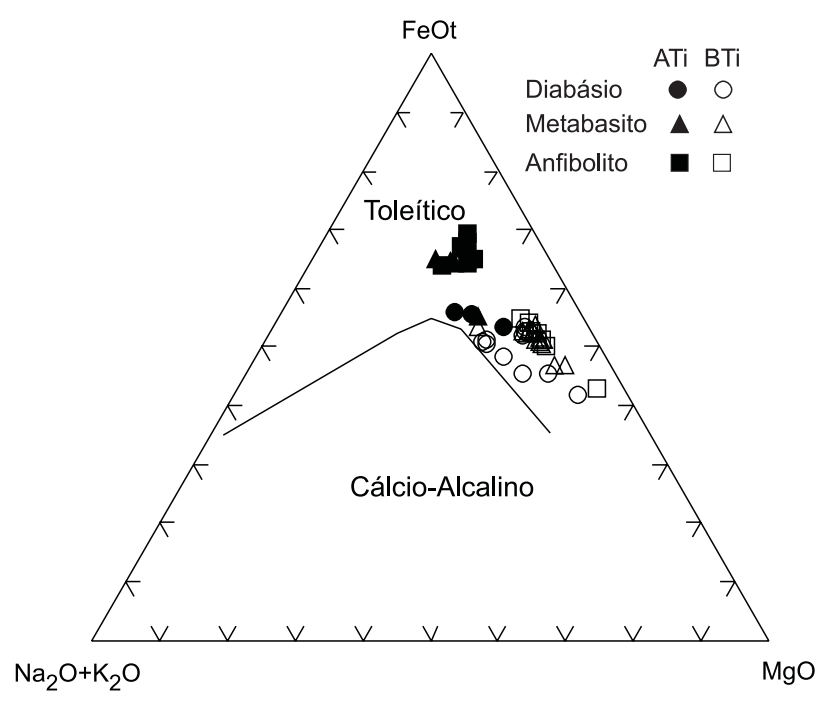

Figura 2. Diagrama AFM $\left(\mathrm{Na}_{2} \mathrm{O}+\mathrm{K}_{2} \mathrm{O}\right)-\mathrm{FeOt}-\mathrm{MgO}$ para classificação geral dos litotipos máficos, segundo a proposta de Irvine e Baragar (1971). Símbolos cheios representam amostras com mais de $1,5 \%$ de $\mathrm{TiO}_{2}$ e vazios representam amostras com menos de $1,5 \%$ de $\mathrm{TiO}_{2}$.

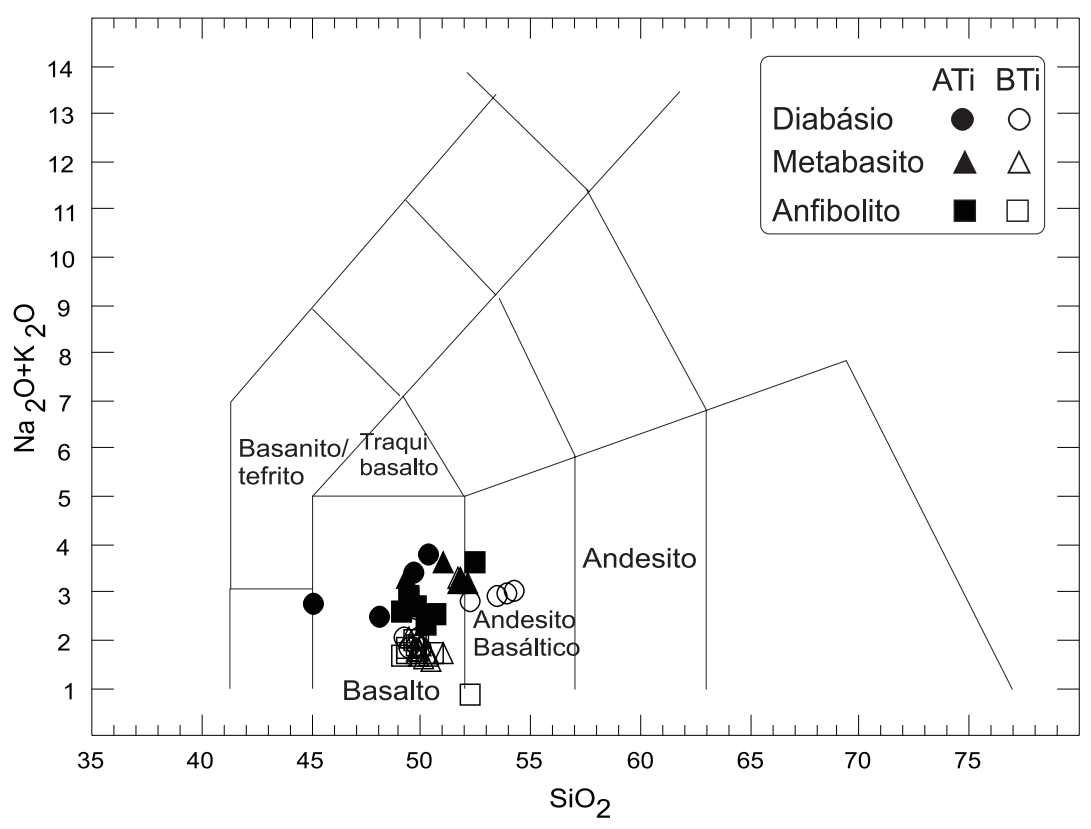

Figura 3. Diagrama de classificação geral dos litotipos máficos, de acordo com a proposta de Le Bas et al. (1986). Símbolos como na Figura 2. 


\section{QUIIMICA MINERAL}

As análises de química mineral quantitativa foram realizadas no Laboratório de Microssonda e Microscopia Eletrônica de Varredura do DMP - Instituto de Geociências - USP, nas fases feldspato, piroxênio, anfibólio e minerais opacos. O aparelho utilizado foi uma microssonda eletrônica JEOL, modelo JXA-8600, equipada com cinco espectrômetros, com cristais STE/TAP, TAP/PET, PET/LIF, PET/LIF e PET/LIF.

Nas análises quantitativas (WDS - Wavelenght Dispersive System) utilizou-se o sistema de análises automatizado Voyager da NORAN Instruments, nas seguintes condições de rotina: voltagem de aceleração $15 \mathrm{KV}$; corrente do feixe eletrônico 20nA; diâmetro de feixe incidente de 10 a $5 \mu \mathrm{m}$ para plagioclásio, $5 \mu \mathrm{m}$ para piroxênio e anfibólio e 5 a $1 \mu \mathrm{m}$ para minerais opacos. Correções quantitativas ZAF para efeitos de matriz $\left(\mathrm{Z}-\mathrm{N}^{0}\right.$ atômico, $\mathrm{A}-$ absorção atômica, $\mathrm{F}$ - fluorescência) foram efetuadas através do programa PROZA de uso interno do laboratório. Os erros analíticos relativos máximos estimados para os resultados são de $\pm 2 \%$ para os elementos maiores e $\pm 5 \%$ para os elementos menores analisados.

A fórmula estrutural dos minerais foi calculada com o auxílio do programa Minpet 2.02, de Richard (1995) que adota os critérios da IMA (International Mineralogical Association). O programa utiliza os métodos de Yoder e Tilley (1962) e Cawthorn e Collerson (1974) para o recálculo do piroxênio e o método de Richard e Clarke (1990) para o recálculo do anfibólio. No caso específico do anfibólio, o programa Minpet oferece 5 métodos diferentes de recálculos (e. g. Robinson et al., 1981). Neste trabalho, optou-se pela média de 15 -NK (os cátions são reajustados para um total de 15, excluindo-se Na e K) e 13 -CNK (os cátions são reajustados para um total de 13 , excluindo-se $\mathrm{Ca}, \mathrm{Na}$ e K). O autor do programa (Richard, 1995) considera o método da média 15 -NK e 13 -CNK mais apropriado para o recálculo dos anfibólios cálcicos.

A partir dos dados de química mineral, foram realizados estudos geotermométricos nas fases piroxênio e plagioclásio. As fórmulas para os cálculos das temperaturas obtidas são encontradas nos trabalhos de Wood e Banno (1973), Ishii (1975), Kretz (1982), Andersen et al. (1998), Kudo e Weill (1970) e Mathez (1973).

Os pontos analisados foram, sempre que possível, localizados nos núcleos (N) e nas bordas (B) dos grãos (fenocristais e/ou microfenocristais).

\section{Piroxênio}

Para a classificação dos piroxênios, adotou-se neste trabalho a nomenclatura de Morimoto (1988), que segue as recomendações da IMA (International Mineralogical Association).

Os dados das composições químicas dos piroxênios ricos (augita) e pobres (enstatita e pigeonita) em cálcio encontram-se nas Tabelas 1 e 2 . Nestas tabelas, estão apresentadas também as respectivas fórmulas estruturais calculadas com base em 6 oxigênios e 4 cátions, bem como, as porcentagens de wollastonita (Wo), enstatita (En) e ferrossilita (Fs). Os valores de $\mathrm{Fe}^{+3}$ foram calculados por balanço de carga a partir do programa Minpet 2.02 de Richard (1995).

Os piroxênios analisados constituem-se essencialmente de $\mathrm{Ca}, \mathrm{Mg}$ e Fe. No diagrama da Figura 4, onde estão representados os componentes moleculares wollastonita (Wo), enstatita (En) e ferrossilita (Fs), pode-se observar a existência de piroxênios ricos e pobres em cálcio tanto no diabásio como no metabasito. Estes piroxênios segundo a nomenclatura de Morimoto (1988), são classificados como augita, seguida de pigeonita e enstatita.

No diagrama da Figura 4 verifica-se que tanto para os piroxênios ricos, quanto pobres em cálcio do diabásio e metabasito, os conteúdos de wollastonita (Wo) decrescem dos núcleos para as bordas dos grãos acompanhados de um aumento dos teores de ferrossilita (Fs). Entretanto, nos piroxênios pobres em cálcio (pigeonita e enstatita), há um fraco incremento em Wo e moderado enriquecimento em Fs.

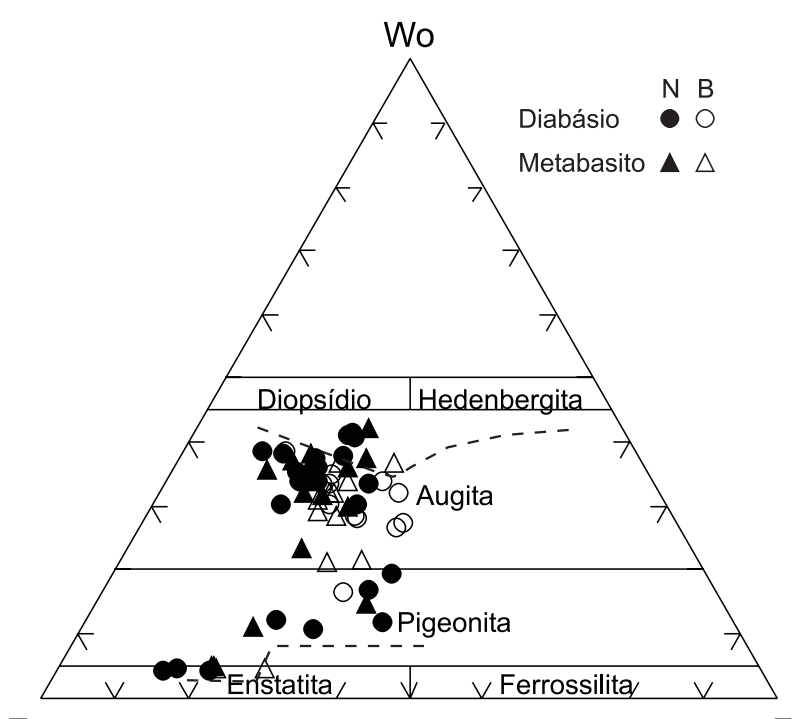

En Fs

Figura 4. Diagrama da variação composicional em função dos componentes moleculares Wo $\left(\mathrm{Ca}_{2} \mathrm{Si}_{2} \mathrm{O}_{6}\right)$, En $\left(\mathrm{Mg}_{2} \mathrm{Si}_{2} \mathrm{O}_{6}\right)$ e Fs $\left(\mathrm{Fe}_{2}^{2} \mathrm{Si}_{2} \mathrm{O}_{6}\right)$ dos piroxênios ricos e pobres em cálcio, para o núcleo ( $\mathbf{N}$ - símbolo cheio) e borda (B - símbolo vazio) dos piroxênios. Linhas tracejadas representam o trend de evolução de Skaergaard. 
Tabela 1. Composição química, em \% de peso, dos piroxênios ricos em cálcio do diabásio e metabasito. Fórmula estrutural calculada com base em 6 átomos de oxigênio. N - núcleo. B - borda. Aug. - augita.

\begin{tabular}{|c|c|c|c|c|c|c|c|c|c|c|c|c|c|c|c|c|c|c|}
\hline \multirow{2}{*}{$\begin{array}{l}\text { Litotipo } \\
\text { Amostra } \\
\end{array}$} & \multicolumn{18}{|c|}{ Diabásio } \\
\hline & CR01 & CR01 & CR01 & CR01 & CR107 & CR107 & CR107 & CR107 & GO05 & GO05 & GO05 & GO05 & GO05 & GO05 & GO06 & G006 & G006 & G006 \\
\hline Fase/Grão & $N / 1$ & $B / 1$ & $N / 2$ & $B / 2$ & $\mathrm{~N} / 1$ & $B / 1$ & $N / 2$ & $B / 2$ & $N / 1$ & $\mathrm{~N} / 2$ & $B / 2$ & $N / 3$ & $B / 3$ & $N / 4$ & $B / 1$ & $N / 2$ & $B / 3$ & $B / 4$ \\
\hline$\overline{\mathrm{SiO}_{2}}$ & 51,35 & 51,50 & 52,05 & 50,85 & 50,70 & 51,46 & 52,01 & 51,82 & 51,09 & 51,49 & 52,02 & 52,11 & 51,07 & 50,86 & 49,10 & 53,03 & 50,76 & 50,40 \\
\hline $\mathrm{Al}_{2} \mathrm{O}_{3}$ & 1,66 & 1,87 & 2,04 & 2,08 & 3,89 & 2,93 & 1,33 & 1,71 & 2,86 & 3,16 & 2,45 & 1,85 & 2,96 & 3,51 & 2,21 & 2,27 & 1,68 & 2,27 \\
\hline $\mathrm{FeO}$ & 16,89 & 17,89 & 10,80 & 19,31 & 11,47 & 13,44 & 16,85 & 17,17 & 12,16 & 10,72 & 14,41 & 12,16 & 14,18 & 13,06 & 21,22 & 10,73 & 21,30 & 17,71 \\
\hline $\mathrm{MnO}$ & 0,36 & 0,38 & 0,28 & 0,44 & 0,19 & 0,27 & 0,31 & 0,34 & 0,25 & 0,19 & 0,34 & 0,30 & 0,32 & 0,25 & 0,51 & 0,38 & 0,50 & 0,29 \\
\hline $\mathrm{MgO}$ & 13,62 & 12,69 & 17,14 & 12,00 & 14,88 & 15,20 & 14,57 & 15,06 & 16,93 & 15,29 & 15,28 & 16,65 & 15,77 & 15,41 & 12,64 & 18,82 & 13,39 & 15,04 \\
\hline $\mathrm{CaO}$ & 16,31 & 16,35 & 17,70 & 15,22 & 16,91 & 16,19 & 14,69 & 13,81 & 15,68 & 18,46 & 15,55 & 16,92 & 15,68 & 14,69 & 12,92 & 15,20 & 12,92 & 13,74 \\
\hline $\mathrm{Na}_{2} \mathrm{O}$ & 0,32 & 0,28 & 0,24 & 0,25 & 0,55 & 0,33 & 0,23 & 0,21 & 0,25 & 0,25 & 0,27 & 0,23 & 0,36 & 0,42 & 0,21 & 0,22 & 0,20 & 0,12 \\
\hline Total & 100,91 & 101,48 & 100,55 & 100,54 & 99,02 & 100,15 & 100,06 & 100,34 & 99,78 & 100,29 & 100,95 & 100,67 & 100,89 & 99,39 & 99,64 & 100,83 & 101,32 & 99,94 \\
\hline$\overline{\mathrm{Si}}$ & 1,93 & 1,94 & 1,91 & 1,94 & 1,90 & 1,92 & 1,97 & 1,95 & 1,89 & 1,90 & 1,93 & 1,92 & 1,89 & 1,91 & 1,89 & 1,93 & 1,92 & 1,90 \\
\hline $\mathrm{Al}^{\mathrm{IV}}$ & 0,07 & 0,06 & 0,09 & 0,06 & 0,10 & 0,08 & 0,04 & 0,05 & 0,11 & 0,10 & 0,07 & 0,08 & 0,11 & 0,09 & 0,10 & 0,07 & 0,08 & 0,10 \\
\hline Total & 2,00 & 2,00 & 2,00 & 2,00 & 2,00 & 2,00 & 2,00 & 2,00 & 2,00 & 2,00 & 2,00 & 2,00 & 2,00 & 2,00 & 1,99 & 2,00 & 2,00 & 2,00 \\
\hline $\mathrm{Al}^{\mathrm{VI}}$ & 0,00 & 0,02 & 0,00 & 0,03 & 0,07 & 0,05 & 0,02 & 0,03 & 0,02 & 0,04 & 0,04 & 0,00 & 0,02 & 0,06 & 0,00 & 0,03 & 0,00 & 0,00 \\
\hline $\mathrm{Ti}$ & 0,01 & 0,01 & 0,01 & 0,01 & 0,01 & 0,01 & 0,00 & 0,01 & 0,02 & 0,02 & 0,02 & 0,01 & 0,02 & 0,03 & 0,02 & 0,01 & 0,02 & 0,01 \\
\hline $\mathrm{Fe}^{3}$ & 0,07 & 0,04 & 0,09 & 0,02 & 0,04 & 0,04 & 0,03 & 0,03 & 0,07 & 0,02 & 0,01 & 0,07 & 0,09 & 0,00 & 0,08 & 0,05 & 0,06 & 0,08 \\
\hline $\mathrm{Fe}^{2}$ & 0,46 & 0,52 & 0,24 & 0,59 & 0,32 & 0,38 & 0,51 & 0,51 & 0,30 & 0,31 & 0,43 & 0,31 & 0,35 & 0,41 & 0,60 & 0,28 & 0,61 & 0,48 \\
\hline $\mathrm{Mn}$ & 0,01 & 0,01 & 0,01 & 0,01 & 0,01 & 0,01 & 0,01 & 0,01 & 0,01 & 0,01 & 0,01 & 0,01 & 0,01 & 0,01 & 0,02 & 0,01 & 0,02 & 0,01 \\
\hline $\mathrm{Ca}$ & 0,66 & 0,66 & 0,70 & 0,62 & 0,68 & 0,65 & 0,60 & 0,56 & 0,62 & 0,73 & 0,62 & 0,67 & 0,62 & 0,59 & 0,53 & 0,59 & 0,52 & 0,56 \\
\hline $\mathrm{Na}$ & 0,02 & 0,02 & 0,02 & 0,02 & 0,04 & 0,02 & 0,02 & 0,02 & 0,02 & 0,02 & 0,02 & 0,02 & 0,03 & 0,03 & 0,02 & 0,02 & 0,02 & 0,01 \\
\hline Total & 2,00 & 2,00 & 2,00 & 2,00 & 2,00 & 2,00 & 2,00 & 2,00 & 1,99 & 1,99 & 2,00 & 2,00 & 2,00 & 2,00 & 2,00 & 2,00 & 2,00 & 1,99 \\
\hline$\overline{\text { WO }}$ & 33,47 & 33,87 & 35,26 & 32,15 & 36,20 & 33,69 & 30,38 & 28,51 & 32,05 & 38,26 & 32,18 & 33,97 & 32,04 & 31,58 & 27,22 & 30,36 & 26,60 & 28,20 \\
\hline EN & 38,89 & 36,58 & 47,51 & 35,27 & 44,32 & 44,03 & 41,92 & 43,26 & 48,15 & 44,09 & 43,99 & 46,51 & 44,83 & 46,09 & 37,05 & 52,31 & 38,36 & 42,95 \\
\hline FS & 27,64 & 29,55 & 17,23 & 32,58 & 19,49 & 22,28 & 27,70 & 28,23 & 19,80 & 17,65 & 23,83 & 19,53 & 23,13 & 22,34 & 35,74 & 17,33 & 35,04 & 28,84 \\
\hline Nome & Aug. & Aug. & Aug. & Aug. & Aug. & Aug. & Aug. & Aug. & Aug. & Aug. & Aug. & Aug. & Aug. & Aug. & Aug. & Aug. & Aug. & Aug. \\
\hline
\end{tabular}

\begin{tabular}{|c|c|c|c|c|c|c|c|c|c|c|c|c|c|}
\hline Litotipo & & & & & & & Diabásio & & & & & & \\
\hline Amostra & G007 & GO07 & G007 & G0113 & G0113 & G0113 & G0113 & G0113 & G0113 & CR110 & CR110 & CR110 & CR110 \\
\hline Fase/Grão & $N / 1$ & $B / 1$ & $N / 2$ & B & $\mathrm{B} / 1$ & $\mathrm{~N} / 2$ & $B / 2$ & $N / 3$ & $N / 4$ & $N / 1$ & $N / 2$ & $N / 3$ & $N / 4$ \\
\hline$\overline{\mathrm{SiO}_{2}}$ & 52,83 & 51,97 & 51,41 & 50,61 & 49,79 & 50,97 & 50,25 & 51,64 & 50,68 & 51,05 & 50,26 & 51,07 & $\overline{50,15}$ \\
\hline $\mathrm{TiO}_{2}$ & 0,28 & 0,37 & 0,48 & 1,08 & 1,43 & 0,81 & 1,15 & 0,67 & 1,15 & 1,27 & 1,18 & 1,13 & 1,59 \\
\hline $\mathrm{Al}_{2} \mathrm{O}_{3}$ & 3,42 & 3,50 & 3,31 & 2,98 & 3,05 & 2,95 & 2,62 & 2,54 & 2,58 & 3,39 & 3,11 & 2,47 & 4,63 \\
\hline $\mathrm{FeO}$ & 6,68 & 8,59 & 8,48 & 14,56 & 13,23 & 10,86 & 13,09 & 12,43 & 11,18 & 12,97 & 13,63 & 13,33 & 12,18 \\
\hline $\mathrm{MnO}$ & 0,16 & 0,23 & 0,18 & 0,37 & 0,29 & 0,28 & 0,27 & 0,29 & 0,23 & 0,31 & 0,30 & 0,20 & 0,29 \\
\hline $\mathrm{MgO}$ & 17,89 & 16,83 & 17,06 & 15,82 & 14,78 & 16,66 & 15,61 & 15,54 & 15,14 & 12,63 & 12,85 & 13,77 & 12,54 \\
\hline $\mathrm{CaO}$ & 19,09 & 19,03 & 18,87 & 14,70 & 16,64 & 16,42 & 16,28 & 16,12 & 18,13 & 19,78 & 19,76 & 18,13 & 19,03 \\
\hline $\mathrm{Na}_{2} \mathrm{O}$ & 0,22 & 0,27 & 0,28 & 0,28 & 0,29 & 0,27 & 0,25 & 0,25 & 0,27 & 0,43 & 0,42 & 0,42 & 0,60 \\
\hline Total & 100,56 & 100,80 & 100,06 & 100,42 & 99,49 & 99,22 & 99,52 & 99,49 & 99,36 & 101,83 & 101,54 & 100,52 & 101,01 \\
\hline$\overline{\mathrm{Si}}$ & 1,92 & 1,89 & 1,89 & 1,89 & 1,88 & 1,90 & 1,89 & 1,94 & 1,90 & 1,89 & 1,87 & 1,91 & 1,86 \\
\hline $\mathrm{Al}^{\mathrm{IV}}$ & 0,08 & 0,11 & 0,12 & 0,11 & 0,12 & 0,10 & 0,11 & 0,06 & 0,10 & 0,11 & 0,13 & 0,09 & 0,14 \\
\hline Total & 2,00 & 2,00 & 2,00 & 2,00 & 2,00 & 2,00 & 2,00 & 2,00 & 2,00 & 2,00 & 2,00 & 2,00 & 2,00 \\
\hline$\overline{\mathrm{Al}^{\mathrm{V}}}$ & 0,06 & 0,04 & 0,03 & 0,02 & 0,01 & 0,03 & 0,00 & 0,05 & 0,02 & 0,04 & 0,00 & 0,02 & 0,07 \\
\hline $\mathrm{Ti}$ & 0,01 & 0,01 & 0,01 & 0,03 & 0,04 & 0,02 & 0,03 & 0,02 & 0,03 & 0,04 & 0,03 & 0,03 & 0,04 \\
\hline $\mathrm{Fe}^{3}$ & 0,02 & 0,06 & 0,08 & 0,06 & 0,05 & 0,05 & 0,07 & 0,00 & 0,04 & 0,03 & 0,09 & 0,04 & 0,02 \\
\hline $\mathrm{Mg}$ & 0,97 & 0,91 & 0,93 & 0,88 & 0,83 & 0,93 & 0,87 & 0,87 & 0,85 & 0,70 & 0,71 & 0,77 & 0,69 \\
\hline $\mathrm{Fe}^{2}$ & 0,18 & 0,20 & 0,18 & 0,40 & 0,36 & 0,29 & 0,35 & 0,39 & 0,31 & 0,37 & 0,33 & 0,38 & 0,36 \\
\hline $\mathrm{Mn}$ & 0,01 & 0,01 & 0,01 & 0,01 & 0,01 & 0,01 & 0,01 & 0,01 & 0,01 & 0,01 & 0,01 & 0,01 & 0,01 \\
\hline $\mathrm{Ca}$ & 0,74 & 0,74 & 0,74 & 0,59 & 0,67 & 0,66 & 0,66 & 0,65 & 0,73 & 0,78 & 0,79 & 0,73 & 0,76 \\
\hline $\mathrm{Na}$ & 0,02 & 0,02 & 0,02 & 0,02 & 0,02 & 0,02 & 0,02 & 0,02 & 0,02 & 0,03 & 0,03 & 0,03 & 0,04 \\
\hline Total & 2,00 & 2,00 & 2,00 & 2,00 & 2,00 & 2,00 & 2,00 & 2,00 & 2,00 & 2,00 & 2,00 & 2,00 & 1,99 \\
\hline$\overline{\text { WO }}$ & 38,70 & 38,57 & 38,23 & 30,39 & 34,84 & 33,99 & 33,62 & 33,82 & 37,68 & 41,45 & 40,73 & 37,89 & 41,18 \\
\hline EN & 50,47 & 47,47 & 48,08 & 45,51 & 43,06 & 48,00 & 44,84 & 45,35 & 43,79 & 36,82 & 36,85 & 40,04 & 37,76 \\
\hline $\mathrm{FS}$ & 10,84 & 13,96 & 13,70 & 24,10 & 22,10 & 18,01 & 21,54 & 20,84 & 18,53 & 21,73 & 22,42 & 22,07 & 21,07 \\
\hline Nome & Aug. & Aug. & Aug. & Aug. & Aug. & Aug. & Aug. & Aug. & Aug. & Aug. & Aug. & Aug. & Aug. \\
\hline
\end{tabular}

(continua...) 
(Tabela 1 - continuação)

\begin{tabular}{|c|c|c|c|c|c|c|c|c|c|c|c|c|c|c|c|c|c|c|}
\hline Litotipo & & & & & & & & & Metab & sito & & & & & & & & \\
\hline Amostra & CR02 & CR09 & CR104 & CR104 & CR104 & CR104 & G013 & G013 & G013 & G013 & G013 & G0100 & G0100 & G0100 & G0100 & G0100 & G0100 & G0100 \\
\hline Fase/Grão & B & B & $N / 1$ & $N / 2$ & $N / 3$ & $B / 4$ & $\mathrm{~N} / 1$ & $B / 1$ & $\mathrm{~N} / 2$ & $B / 2$ & $\mathrm{~B} / 3$ & $\mathrm{~N} / 1$ & $\mathrm{~N} / 2$ & $\mathrm{~B} / 2$ & $\mathrm{~N} / 3$ & $\mathrm{~B} / 3$ & N/4 & $\mathrm{B} / 4$ \\
\hline$\overline{\mathrm{SiO}_{2}}$ & 52,25 & 53,60 & 52,31 & 51,36 & $\overline{51,52}$ & 51,07 & 50,37 & 51,47 & 52,43 & $\overline{50,48}$ & 50,98 & 49,76 & 51,00 & $\overline{51,16}$ & $\overline{50,04}$ & 49,70 & 50,34 & $\overline{50,17}$ \\
\hline $\mathrm{TiO}_{2}$ & 0,23 & 0,17 & 0,54 &, 40 & 0,20 & ,59 & 0,52 & 0,03 & 0,30 & 0,50 & 0,37 & 0,91 & 0,70 & 0,62 & 0,80 & 0,91 & 0,78 & 0,75 \\
\hline $\mathrm{Al}_{2} \mathrm{O}_{3}$ & 6,09 & 5,58 & 2,91 & 2,71 & 0,98 & 1,43 & 2,01 & 1,50 & 1,82 & 1,70 & 1,74 & 2,32 & 2,56 & 2,42 & 2,53 & 1,70 & 2,96 & 2,49 \\
\hline $\mathrm{FeO}$ & 12,61 & 14,05 & 7,95 & 9,56 & 14,17 & 13,26 & 16,09 & 17,55 & 14,73 & 20,11 & 13,58 & 15,28 & 11,23 & 11,32 & 14,25 & 17,61 & 11,41 & 14,88 \\
\hline $\mathrm{MnO}$ & 0,23 & 0,29 & 22 & ,24 & ,28 & 0,31 &, 41 & 0,42 & 0,40 & 0,40 & 0,38 & 0,29 & 0,19 & 0,26 & 0,33 & 0,40 & 0,26 & 0,27 \\
\hline $\mathrm{MgO}$ & 14,85 & 14,14 & 18,12 & 16,62 & 11,99 & 14,30 & 15,14 & 17,88 & 19,03 & 15,93 & 16,47 & 12,75 & 16,03 & 16,10 & 13,97 & 11,50 & 15,69 & 14,32 \\
\hline $\mathrm{Na}_{2} \mathrm{O}$ & 0,42 & 0,49 & 0,18 & 0,25 & 0,42 & 0,34 & 0,25 & 0,20 & 0,17 & 0,23 & 0,22 & 0,31 & 0,32 & 0,33 & 0,33 & 0,32 & 0,31 & 0,38 \\
\hline Total & 99,39 & 00,68 & 99,80 & 99,38 & 100,06 & 100,03 & 99,26 & 99,52 & 100,68 & 99,89 & 99,07 & 99,47 & 99,71 & 99,39 & 99,70 & 99,67 & 99,72 & 99,45 \\
\hline$\overline{\mathrm{Si}}$ & 1,95 & 1,99 & 1,92 & 1,91 & 1,95 & 1,92 & 1,91 & 1,93 & 1,93 & 1,91 & 1,92 & 1,90 & 1,90 & 1,91 & 1,89 & 1,91 & 1,88 & 1,90 \\
\hline $\mathrm{Al}^{\mathrm{IV}}$ & 0,05 & 0,01 & 0,08 & 0,10 & 0,04 & 0,06 & 0,09 & 0,07 & 0,07 & 0,08 & 0,08 & 0,10 & 0,10 & 0,09 & 0,11 & 0,08 & 0,13 & 0,10 \\
\hline Total & 2,00 & 2,00 & 2,00 & 2,00 & 2,00 & 1,99 & 2,00 & 2,00 & 2,00 & 1,99 & 1,99 & 2,00 & 2,00 & 2,00 & 2,00 & 1,99 & 2,00 & 2,00 \\
\hline$\overline{\mathrm{Al}^{\mathrm{VI}}}$ & 0,22 & 0,24 & 0,04 & 02 & 0,00 & 0,00 & 0,00 & 0,00 & 0,01 & 0,00 & 0,00 & 0,00 & 01 & 0,02 &, 00 & 0,00 & 00 & 0,01 \\
\hline $\mathrm{Ti}$ & 0,01 & 0,01 & 0,02 & 0,01 & 0,01 & 0,05 & 0,02 & 0,00 & 0,01 & 0,01 & 0,01 & 0,03 & 0,02 & 0,02 & 0,02 & 0,03 & 0,02 & 0,02 \\
\hline $\mathrm{Fe}^{3}$ & 0,00 & 0,00 & 0,02 & 0,07 & 0,07 & 0,01 & 0,08 & 0,08 & 0,06 & 0,07 & 0,08 & 0,07 & 0,08 & 0,07 & 0,09 & 0,06 & 0,10 & 0,08 \\
\hline $\mathrm{Fe}^{2}$ & 0,39 & 0,44 & 0,22 & 0,23 & 0,38 & 0,39 & 0,43 & 0,47 & 0,39 & 0,55 & 0,34 & 0,42 & 0,27 & 0,29 & 0,36 & 0,50 & 0,26 & 0,39 \\
\hline $\mathrm{Mn}$ & 0,01 & 0,01 & 0,01 & 0,01 & 0,01 & 0,01 & 0,01 & 0,01 & 0,01 & 0,01 & 0,01 & 0,01 & 0,01 & 0,01 & 0,01 & 0,01 & 0,01 & 0,01 \\
\hline $\mathrm{Ca}$ & 0,51 & 0,49 & 0,69 & 0,72 & 0,83 & 0,72 & 0,59 & 0,42 & 0,47 & 0,43 & 0,62 & 0,73 & 0,71 & 0,69 & 0,71 & 0,72 & 0,72 & 0,66 \\
\hline $\mathrm{Na}$ & 0,03 & 0,04 & 0,01 & 0,02 & 0,03 & 0,03 & 0,02 & 0,02 & 0,01 & 0,02 & 0,02 & 0,02 & 0,02 & 0,02 & 0,02 & 0,02 & 0,02 & 0,03 \\
\hline Total & 1,99 & 1,99 & 2,00 & 2,00 & 2,00 & 2,00 & 2,00 & 2,00 & 2,00 & 2,00 & 2,00 & 2,00 & 2,00 & 2,00 & 2,00 & 2,00 & 2,00 & 2,00 \\
\hline$\overline{\text { WO }}$ & 29,13 & 28,46 & 35,77 & 37,20 & 42,29 & 36,79 & 29,89 & 21,14 & 23,56 & 21,64 & 31,18 & 37,41 & 36,16 & 35,34 & 36,17 & 36,85 & 36,74 & 33,78 \\
\hline EN & 47,72 & 45,60 & 51,27 & 47,19 & 34,43 & 41,25 & 43,51 & 50,42 & 52,86 & 45,50 & 46,64 & 37,15 & 45,61 & 46,06 & 40,26 & 33,61 & 44,62 & 41,56 \\
\hline $\mathrm{FS}$ & 23,15 & 25,95 & 12,96 & 15,61 & 23,28 & 21,96 & 26,61 & 28,44 & 23,58 & 32,87 & 22,18 & 25,45 & 18,23 & 18,60 & 23,57 & 29,54 & 18,64 & 24,66 \\
\hline Nome & Aug. & Aug. & Aug. & Aug. & Aug. & Aug. & Aug. & Aug. & Aug. & Aug. & Aug. & Aug. & Aug. & Aug. & Aug. & Aug. & Aug. & Aug. \\
\hline
\end{tabular}

Tabela 2. Composição química, em \% de peso, dos piroxênios pobres em cálcio. Fórmula estrutural calculada com base em 6 átomos de oxigênio. N - núcleo. B - borda. Pig. - pigeonita. En - enstatita.

\begin{tabular}{|c|c|c|c|c|c|c|c|c|c|c|c|c|c|c|c|}
\hline \multirow{2}{*}{$\begin{array}{l}\text { Litotipo } \\
\text { Amostra }\end{array}$} & \multicolumn{9}{|c|}{ Diabásio } & \multicolumn{6}{|c|}{ Metabasito } \\
\hline & CR01 & CR01 & G006 & G006 & G006 & G006 & G007 & G007 & G007 & CR104 & CR104 & CR104 & CR104 & G013 & G013 \\
\hline Fase/Grão & $N / 1$ & $N / 2$ & $\mathrm{~N} / 1$ & $B / 2$ & $N / 3$ & $N / 4$ & $\mathrm{~N} / \mathbf{1}$ & $N / 2$ & $\mathrm{~N} / 3$ & N/1 & $B / 1$ & $N / 2$ & $B / 2$ & N/1 & $N / 3$ \\
\hline$\overline{\mathrm{SiO}_{2}}$ & 52,12 & 51,40 & 50,63 & 51,27 & 53,67 & $\overline{52,07}$ & 55,92 & 54,95 & 56,44 & 54,08 & 53,05 & $\overline{54,16}$ & 53,91 & $\overline{53,91}$ & $\overline{53,01}$ \\
\hline $\mathrm{TiO}_{2}$ & 0,06 & 0,08 & 0,27 & 0,44 & 0,24 & 1,05 & 0,14 & 0,10 & 0,06 & 0,21 & 0,23 & 0,25 & 0,21 & 0,28 & 0,24 \\
\hline $\mathrm{Al}_{2} \mathrm{O}_{3}$ & 1,09 & 1,15 & 1,84 & 1,67 & 1,56 & 2,04 & 1,52 & 1,76 & 0,84 & 2,12 & 1,57 & 1,96 & 2,01 & 0,74 & 1,71 \\
\hline $\mathrm{FeO}$ & 24,46 & 19,82 & 22,07 & 20,17 & 16,47 & 21,44 & 10,65 & 13,62 & 9,70 & 13,48 & 17,92 & 13,28 & 13,76 & 20,84 & 14,69 \\
\hline $\mathrm{MnO}$ & 0,61 & 0,36 & 0,42 & 0,45 & 0,43 & 0,39 & 0,24 & 0,28 & 0,24 & 0,27 & 0,29 & 0,32 & 0,29 & 0,49 & 0,36 \\
\hline $\mathrm{MgO}$ & 16,48 & 20,65 & 16,40 & 17,79 & 22,83 & 13,75 & 29,97 & 28,02 & 31,41 & 27,36 & 24,58 & 27,24 & 27,23 & 15,85 & 23,93 \\
\hline $\mathrm{CaO}$ & 5,78 & 5,39 & 8,13 & 8,14 & 6,30 & 8,74 & 2,38 & 2,17 & 2,28 & 2,54 & 2,42 & 2,47 & 2,37 & 6,77 & 5,68 \\
\hline $\mathrm{Na}_{2} \mathrm{O}$ & 0,23 & 0,14 & 0,19 & 0,18 & 0,10 & 0,25 & 0,03 & 0,06 & 0,03 & 0,03 & 0,01 & 0,03 & 0,00 & 0,13 & 0,17 \\
\hline Total & 00,83 & 99,01 & 99,96 & 100,13 & 101,62 & 99,85 & 100,85 & 100,96 & 100,99 & 100,10 & 100,08 & 99,72 & 99,78 & 99,04 & 99,80 \\
\hline$\overline{\mathrm{Si}}$ & 1,97 & 1,93 & 1,92 & 1,92 & 1,94 & 2,00 & 1,96 & 1,95 & 1,96 & 1,94 & 1,94 & 1,95 & 1,94 & 2,07 & 1,93 \\
\hline $\mathrm{Al}^{\mathrm{IV}}$ & 0,03 & 0,05 & 0,08 & 0,07 & 0,06 & 0,00 & 0,04 & 0,05 & 0,03 & 0,07 & 0,06 & 0,05 & 0,06 & 0,00 & 0,07 \\
\hline Total & 2,00 & 1,98 & 2,00 & 2,00 & 2,00 & 2,00 & 2,00 & 2,00 & 2,00 & 2,00 & 2,00 & 2,00 & 2,00 & 2,07 & 2,00 \\
\hline$\overline{\mathrm{Al}^{\mathrm{VI}}}$ & 0,02 & 0,00 & 0,00 & 0,00 & 0,00 & 0,09 & 0,02 & 0,02 & 0,00 & 0,02 & 0,00 & 0,03 & 0,02 & 0,03 & 0,00 \\
\hline $\mathrm{Ti}$ & 0,00 & 0,00 & 0,01 & 0,01 & 0,01 & 0,03 & 0,00 & 0,00 & 0,00 & 0,01 & 0,01 & 0,01 & 0,01 & 0,01 & 0,01 \\
\hline $\mathrm{Fe}^{3}$ & 0,02 & 0,08 & 0,07 & 0,06 & 0,06 & 0,00 & 0,01 & 0,03 & 0,04 & 0,03 & 0,05 & 0,02 & 0,03 & 0,00 & 0,07 \\
\hline $\mathrm{Mg}$ & 0,93 & 1,15 & 0,93 & 1,00 & 1,23 & 0,79 & 1,57 & 1,48 & 1,63 & 1,46 & 1,34 & 1,46 & 1,46 & 0,91 & 1,30 \\
\hline $\mathrm{Fe}^{2}$ & 0,75 & 0,53 & 0,63 & 0,57 & 0,44 & 0,69 & 0,30 & 0,37 & 0,24 & 0,37 & 0,50 & 0,38 & 0,38 & 0,67 & 0,38 \\
\hline $\mathrm{Mn}$ & 0,02 & 0,01 & 0,01 & 0,01 & 0,01 & 0,01 & 0,01 & 0,01 & 0,01 & 0,01 & 0,01 & 0,01 & 0,01 & 0,02 & 0,01 \\
\hline $\mathrm{Ca}$ & 0,23 & 0,22 & 0,33 & 0,33 & 0,24 & 0,36 & 0,09 & 0,08 & 0,09 & 0,10 & 0,10 & 0,10 & 0,09 & 0,28 & 0,22 \\
\hline $\mathrm{Na}$ & 0,02 & 0,01 & 0,01 & 0,01 & 0,01 & 0,02 & 0,00 & 0,00 & 0,00 & 0,00 & 0,00 & 0,00 & 0,00 & 0,01 & 0,01 \\
\hline Tota & 2,00 & 1,99 & 2,00 & 1,99 & 2,00 & 1,99 & 2,00 & 2,00 & 2,00 & 2,00 & 2,00 & 2,00 & 2,00 & 1,93 & 2,00 \\
\hline$\overline{\text { WO }}$ & 11,97 & 10,81 & 16,76 & 16,62 & 12,29 & 19,46 & 4,52 & 4,17 & 4,24 & 4,95 & 4,76 & 4,85 & 4,62 & 14,89 & 11,20 \\
\hline EN & 47,49 & 57,61 & 47,04 & 50,52 & 61,97 & 42,60 & 79,32 & 74,97 & 81,32 & 74,15 & 67,28 & 74,33 & 73,96 & 48,49 & 65,64 \\
\hline FS & 40,54 & 31,59 & 36,20 & 32,86 & 25,74 & 37,95 & 16,16 & 20,86 & 14,44 & 20,90 & 27,96 & 20,82 & 21,42 & 36,62 & 23,17 \\
\hline Nom & Pig. & Pig. & Pig. & Pig. & Pig. & Pig. & En & En & En & En & En & En & En & Pig. & Pig. \\
\hline
\end{tabular}


Observa-se também, na Figura 4, que os piroxênios ricos em cálcio posicionam-se abaixo do trend de evolução de Skaergaard (Brown, 1957; Brown e Vincent, 1963), e os piroxênios pobres em cálcio se aproximam do trend de evolução de Skaergaard. Segundo Wager e Brown (1968), a coexistência de piroxênios ricos e pobres em cálcio e a evolução acompanhada de um decréscimo nos conteúdos de cálcio e aumento nos conteúdos de ferro, é típica de suítes toleíticas.

Com o objetivo de conhecer as temperaturas dos piroxênios, foram utilizados os geotermômetros propostos por Wood e Banno (1973), Kretz (1982) e Andersen et al. (1998), para o par augita coexistente com pigeonita e/ou enstatita e o geotermômetro de Ishii (1975) aplicado exclusivamente em pigeonitas. Estes geotermômetros utilizam-se de equações que fornecem a temperatura de equilíbrio em associações minerais contendo dois piroxênios, pois a composição desses minerais é bastante sensível a variações de temperatura.

A Tabela 3 apresenta os valores das temperaturas, em graus centígrados, obtidos para cada par de piroxênios usado como geotermômetro.

Os valores médios de temperatura obtidos para os diques de diabásio nos núcleos $(\mathrm{N})$ e bordas $(\mathrm{B})$ dos grãos foram respectivamente $1177^{\circ} \mathrm{C}(\mathrm{N})$ e $1163^{\circ} \mathrm{C}(\mathrm{B})$ pelo geotermômetro de $\operatorname{Kretz}(1982) ; 1139^{\circ} \mathrm{C}(\mathrm{N})$ e $1118^{\circ} \mathrm{C}$ (B) pelo geotermômetro de Wood e Banno (1973); $1145^{\circ} \mathrm{C}(\mathrm{N})$ e $1095^{\circ} \mathrm{C}(\mathrm{B})$ pelo geotermômetro de Ishii $(1975) ; 1169^{\circ} \mathrm{C}(\mathrm{N}) \mathrm{e}$ $1080^{\circ} \mathrm{C}$ (B) pelo geotermômetro de Andersen et al. (1998).

Quando se avalia o conjunto dos metabasitos, obtém-se os seguintes valores médios para os núcleos $(\mathrm{N})$ e bordas (B) dos grãos respectivamente: $1204^{\circ} \mathrm{C}(\mathrm{N})$ e $1099^{\circ} \mathrm{C}(\mathrm{B})$ pelo geotermômetro de $\mathrm{Kretz}(1982) ; 1111^{\circ} \mathrm{C}(\mathrm{N})$ e $1083^{\circ} \mathrm{C}$ (B) pelo geotermômetro de Wood e Banno (1973); $1167^{\circ} \mathrm{C}(\mathrm{N})$ e $1139^{\circ} \mathrm{C}(\mathrm{B})$ pelo geotermômetro de Ishii $(1975), 1167^{\circ} \mathrm{C}(\mathrm{N}) \mathrm{e}$ $1109^{\circ} \mathrm{C}$ (B) pelo geotermômetro de Andersen et al. (1998).

Piroxênios com composições semelhantes a estes foram encontrados em diques máficos do nordeste da Bahia, sul de Minas Gerais e centro-leste da Argentina (e. g. Menezes Leal et al., 1995; Pinese, 1997; Iacumin et al., 2001), fornecendo valores de temperaturas obtidas pelos métodos de Wood e Banno (1973), Ishii (1975) e Kretz (1982) próximas às temperaturas encontradas para as rochas dos diques de Goiás por estes mesmos geotermômetros utilizados.

\section{Plagioclásio}

Os plagioclásios foram classificados no sistema ternário Albita (Ab), Anortita (An) e Ortoclásio (Or), conforme as recomendações de Deer et al. (1992). Os resultados das microanálises químicas dos plagioclásios correspondentes aos núcleos e bordas dos grãos estão na Tabela 4.
Tabela 3. Temperatura dos piroxênios e o seu valor médio para os diques de diabásio e metabasito. $\mathrm{N}$ - núcleo. B - borda. $\mathbf{n}$ - número de amostras. $\mathbf{T}_{\text {Kretz }}$ - Temperatura Kretz (1982). T Tood e Banno - Temperatura Wood e Banno (1973). T $T_{\text {shii }}$ - Temperatura Ishii (1975). $\mathrm{T}_{\text {Andersen }}$ - Temperatura Andersen et al. (1998).

\begin{tabular}{|c|c|c|c|c|c|c|}
\hline \multirow{2}{*}{\multicolumn{2}{|c|}{ Amostra }} & \multirow{2}{*}{ Fase } & \multicolumn{4}{|c|}{ Geotermômetros ( ${ }^{\circ} \mathrm{C}$ ) } \\
\hline & & & $\mathrm{T}_{\text {Kretz }}$ & $T_{\text {Wood e Banno }}$ & $\mathrm{T}_{\text {Ishii }}$ & $\mathrm{T}_{\text {Andersen }}$ \\
\hline \multirow{12}{*}{$\begin{array}{l}\frac{0}{n} \\
\frac{0}{0} \\
\frac{0}{0} \\
\frac{\pi}{0}\end{array}$} & \multirow{2}{*}{ CR01 } & $\mathrm{N}$ & 1139 & 1090 & 1119 & 1224 \\
\hline & & $\mathrm{B}$ & 1118 & 1065 & - & 1083 \\
\hline & \multirow{2}{*}{ CR107 } & $\mathrm{N}$ & 1148 & 1141 & - & 1116 \\
\hline & & B & 1178 & 1136 & - & - \\
\hline & \multirow{2}{*}{ GO05 } & $\mathrm{N}$ & 1232 & 1102 & - & 1183 \\
\hline & & $\mathrm{B}$ & 1195 & 1088 & - & 1084 \\
\hline & \multirow{2}{*}{ Go06 } & $\mathrm{N}$ & 1203 & 1094 & 1143 & 1162 \\
\hline & & $\mathrm{B}$ & 1188 & 1064 & 1095 & 1218 \\
\hline & \multirow{2}{*}{ GO07 } & $\mathrm{N}$ & 1164 & 1266 & 1174 & 1161 \\
\hline & & $\mathrm{B}$ & 1134 & 1236 & - & 938 \\
\hline & \multirow{2}{*}{ Média } & $\mathrm{N}$ & $\begin{array}{l}1177 \\
(n=5)\end{array}$ & $\begin{array}{l}1139 \\
(n=5)\end{array}$ & $\begin{array}{l}1145 \\
(n=3)\end{array}$ & $\begin{array}{l}1169 \\
(n=5)\end{array}$ \\
\hline & & B & $\begin{array}{l}1163 \\
(n=5)\end{array}$ & $\begin{array}{l}1118 \\
(n=5)\end{array}$ & $\begin{array}{l}1095 \\
(n=1)\end{array}$ & $\begin{array}{l}1080 \\
(n=4)\end{array}$ \\
\hline \multirow{9}{*}{ 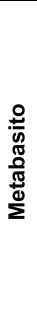 } & \multirow{2}{*}{ CR104 } & $\mathrm{N}$ & 1155 & 1120 & 1172 & 1263 \\
\hline & & $\mathrm{B}$ & 946 & 1160 & 1139 & 1176 \\
\hline & \multirow{2}{*}{ G013 } & $\mathrm{N}$ & 1345 & 1147 & 1161 & 1200 \\
\hline & & B & 1298 & 1083 & - & 1076 \\
\hline & \multirow{2}{*}{ G0100 } & $\mathrm{N}$ & 1111 & 1065 & - & 1038 \\
\hline & & B & 1052 & 1005 & - & 1076 \\
\hline & \multirow{3}{*}{ Média } & & 1204 & 1111 & 1167 & 1167 \\
\hline & & IN & $(n=3)$ & $(n=3)$ & $(n=2)$ & $(n=3)$ \\
\hline & & B & $\begin{array}{l}1099 \\
(n=3)\end{array}$ & $\begin{array}{l}1083 \\
(n=3)\end{array}$ & $\begin{array}{l}1139 \\
(n=1)\end{array}$ & $\begin{array}{l}1109 \\
(n=3)\end{array}$ \\
\hline
\end{tabular}

No diagrama da Figura 5 estão representadas as análises dos núcleos dos grãos de plagioclásio. Nesta figura, observa-se que os plagioclásios distribuem-se da seguinte maneira: No diabásio, há um predomínio da composição labradorítica (An 67,6 - 55,0), embora, em algumas análises das amostras CR01 e CR110 ocorra uma ligeira variação dos conteúdos de anortita que são correspondentes à composição bytownítica (An 79,1 -75,0). No metabasito, a composição do plagioclásio é exclusivamente labradorítica (An 69,3 -49,1). Enquanto, que nos anfibolitos há uma variação dos conteúdos de anortita que vão de andesina (An 39,3 - 37,5) a oligoclásio (An 29,0-22,1).

Variações muito pequenas ocorrem nas bordas dos plagioclásios. Labradoritas (An 68,8-50,4 e An 64,6-52,2) ocorrem respectivamente em diabásio e metabasito. Andesina-oligoclásio (An 31,0-28,4) aparecem nas bordas do anfibolito.

Para a determinação das temperaturas dos estágios de cristalização dos plagioclásios utilizaram-se os geotermômetros de Kudo e Weill (1970) e Mathez (1973), assumindo condições anidras. Os valores das temperaturas obtidos para cada amostra, em graus centígrados, estão na Tabela 5. 
Tabela 4. Composição química, em \% de peso, dos plagioclásios. Fórmula estrutural calculada com base em 32 átomos de oxigênio. N - núcleo. B - borda. lab. - labradorita. byłow. - bytownita. and. - andesina. olig. - oligoclásio.

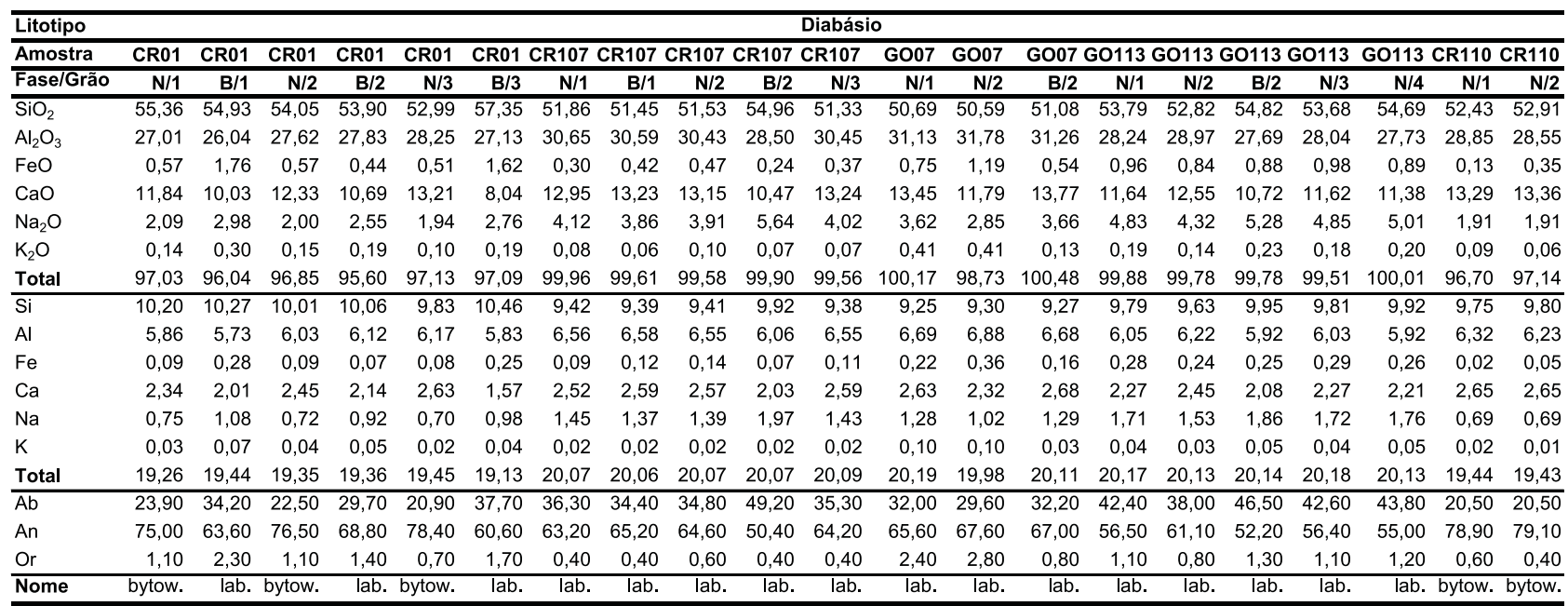

\begin{tabular}{|c|c|c|c|c|c|c|c|c|c|c|c|c|}
\hline \multirow{2}{*}{$\begin{array}{l}\text { Litotipo } \\
\text { Amostra }\end{array}$} & \multicolumn{12}{|c|}{ Metabasito } \\
\hline & CR02 & CR02 & CR09 & CR104 & CR104 & CR104 & CR104 & CR104 & CR104 & $\overline{\text { G013 }}$ & G0100 & G0100 \\
\hline Fase/Grão & $\bar{N}$ & $\bar{B}$ & $\bar{N}$ & $\mathrm{~N} / 1$ & $\mathrm{~B} / 1$ & $\mathrm{~N} / 2$ & $\mathrm{~B} / 2$ & $\mathrm{~N} / 3$ & $\mathrm{~B} / 3$ & $\bar{N}$ & $\bar{N} / 1$ & $\mathrm{~N} / 2$ \\
\hline$\overline{\mathrm{SiO}_{2}}$ & 59,15 & 58,11 & 53,21 & 53,54 & 54,19 & 50,94 & 51,73 & 52,23 & 57,69 & 53,68 & 52,55 & $\overline{54,78}$ \\
\hline $\mathrm{Al}_{2} \mathrm{O}_{3}$ & 24,89 & 26,75 & 27,70 & 29,56 & 27,90 & 31,52 & 30,78 & 30,40 & 27,13 & 28,57 & 28,76 & 27,87 \\
\hline $\mathrm{FeO}$ & 0,30 & 0,30 & 0,91 & 0,56 & 1,32 & 0,17 & 0,52 & 0,32 & 0,01 & 0,68 & 1,33 & 0,81 \\
\hline $\mathrm{CaO}$ & 6,72 & 7,93 & 11,92 & 11,87 & 10,77 & 13,78 & 13,38 & 12,68 & 8,92 & 10,86 & 10,24 & 10,15 \\
\hline $\mathrm{Na}_{2} \mathrm{O}$ & 3,81 & 3,65 & 2,87 & 4,80 & 5,38 & 3,81 & 4,02 & 4,37 & 6,48 & 3,01 & 4,99 & 5,56 \\
\hline $\mathrm{K}_{2} \mathrm{O}$ & 0,07 & 0,08 & 0,07 & 0,08 & 0,11 & 0,04 & 0,05 & 0,07 & 0,09 & 0,06 & 0,65 & 0,21 \\
\hline Total & 95,14 & 96,82 & 96,68 & 100,50 & 99,79 & 100,28 & 100,56 & 100,20 & 100,33 & 96,86 & 98,60 & 99,51 \\
\hline$\overline{\mathrm{Si}}$ & 10,91 & 10,57 & 9,91 & 9,66 & 9,86 & 9,25 & 9,37 & 9,47 & 10,30 & 9,93 & 9,70 & $\overline{9,96}$ \\
\hline $\mathrm{Al}$ & 5,40 & 5,73 & 6,08 & 6,28 & 5,98 & 6,74 & 6,56 & 6,49 & 5,70 & 6,22 & 6,25 & 5,97 \\
\hline $\mathrm{Fe}$ & 0,05 & 0,05 & 0,14 & 0,16 & 0,38 & 0,05 & 0,15 & 0,09 & 0,00 & 0,11 & 0,39 & 0,23 \\
\hline $\mathrm{Ca}$ & 1,33 & 1,55 & 2,38 & 2,30 & 2,10 & 2,68 & 2,60 & 2,46 & 1,71 & 2,15 & 2,03 & 1,98 \\
\hline $\mathrm{Na}$ & 1,36 & 1,29 & 1,04 & 1,68 & 1,90 & 1,34 & 1,41 & 1,54 & 2,24 & 1,08 & 1,79 & 1,96 \\
\hline K & 0,02 & 0,02 & 0,02 & 0,02 & 0,03 & 0,01 & 0,01 & 0,02 & 0,02 & 0,01 & 0,15 & 0,05 \\
\hline Total & 19,09 & 19,21 & 19,57 & 20,11 & 20,26 & 20,07 & 20,11 & 20,09 & 19,97 & 19,50 & 20,32 & 20,16 \\
\hline$\overline{\mathrm{Ab}}$ & 50,40 & 45,10 & 30,20 & 42,10 & 47,20 & 33,20 & 35,10 & 38,30 & 56,50 & 33,30 & 45,10 & 49,20 \\
\hline An & 49,10 & 54,20 & 69,30 & 57,50 & 52,20 & 66,50 & 64,60 & 61,40 & 43,00 & 66,30 & 51,10 & 49,60 \\
\hline Or & 0,60 & 0,70 & 0,50 & 0,50 & 0,60 & 0,20 & 0,30 & 0,40 & 0,50 & 0,40 & 3,80 & 1,20 \\
\hline Nome & lab. & lab. & lab. & lab. & lab. & lab. & Tab. & lab. & lab. & lab. & lab. & lab. \\
\hline
\end{tabular}

\begin{tabular}{lrrrrrrrrrrr}
\hline Litotipo & \multicolumn{10}{c}{ Anfibolito } \\
\hline Amostra & CR105 & CR105 & CR105 & CR105 & CR105 & CR105 & G0101 & G0101 & G0101 & G0101 & G0101 \\
\hline Fase/Grão & $\mathbf{N} / 1$ & $\mathbf{B} / 1$ & N/2 & N/3 & N/4 & N/5 & N/1 & B/1 & N/2 & B/2 & B/3 \\
\hline $\mathrm{SiO}_{2}$ & 61,03 & 59,72 & 60,45 & 61,97 & 62,66 & 60,67 & 53,78 & 55,34 & 53,55 & 54,57 & 55,76 \\
$\mathrm{Al}_{2} \mathrm{O}_{3}$ & 24,28 & 25,05 & 24,43 & 24,22 & 23,36 & 24,64 & 25,24 & 23,97 & 26,38 & 26,01 & 23,94 \\
$\mathrm{FeO}$ & 0,16 & 0,20 & 0,16 & 0,10 & 0,10 & 0,12 & 0,18 & 0,25 & 0,04 & 0,07 & 0,16 \\
$\mathrm{CaO}$ & 5,78 & 6,43 & 5,85 & 5,35 & 4,69 & 6,09 & 9,29 & 7,76 & 9,19 & 7,19 & 7,13 \\
$\mathrm{Na}{ }_{2} \mathrm{O}$ & 8,44 & 7,87 & 8,19 & 8,82 & 9,11 & 8,22 & 8,30 & 9,42 & 7,58 & 8,86 & 9,60 \\
$\mathrm{~K}_{2} \mathrm{O}$ & 0,09 & 0,08 & 0,11 & 0,10 & 0,07 & 0,04 & 0,39 & 0,45 & 0,43 & 0,48 & 0,48 \\
Total & 99,80 & 99,43 & 99,20 & 100,70 & 100,07 & 99,79 & 97,27 & 97,22 & 97,18 & 97,19 & 97,07 \\
\hline $\mathrm{Si}$ & 10,88 & 10,70 & 10,84 & 10,94 & 11,09 & 10,81 & 10,08 & 10,35 & 10,01 & 10,16 & 10,42 \\
$\mathrm{Al}$ & 5,09 & 5,29 & 5,16 & 5,04 & 4,87 & 5,17 & 5,57 & 5,28 & 5,81 & 5,71 & 5,27 \\
$\mathrm{Fe}$ & 0,05 & 0,06 & 0,05 & 0,03 & 0,03 & 0,03 & 0,05 & 0,08 & 0,01 & 0,02 & 0,05 \\
$\mathrm{Ca}$ & 1,10 & 1,24 & 1,12 & 1,01 & 0,89 & 1,16 & 1,87 & 1,56 & 1,84 & 1,43 & 1,43 \\
$\mathrm{Na}$ & 2,92 & 2,73 & 2,85 & 3,02 & 3,13 & 2,84 & 3,02 & 3,42 & 2,74 & 3,20 & 3,48 \\
$\mathrm{~K}$ & 0,02 & 0,02 & 0,03 & 0,02 & 0,02 & 0,01 & 0,09 & 0,11 & 0,10 & 0,12 & 0,12 \\
Total & 20,06 & 20,05 & 20,04 & 20,08 & 20,04 & 20,03 & 20,70 & 20,79 & 20,51 & 20,64 & 20,76 \\
\hline Ab & 72,20 & 68,60 & 71,20 & 74,50 & 77,50 & 70,80 & 60,70 & 67,30 & 58,60 & 67,40 & 69,30 \\
An & 27,30 & 31,00 & 28,10 & 24,90 & 22,10 & 29,00 & 37,50 & 30,60 & 39,30 & 30,20 & 28,40 \\
Or & 0,50 & 0,50 & 0,60 & 0,50 & 0,40 & 0,20 & 1,80 & 2,10 & 2,20 & 2,40 & 2,30 \\
\hline Nome & olig. & and. & olig. & olig. & olig. & olig. & and. & and. & and. & and. & olig. \\
\hline
\end{tabular}


Para os diques de diabásio, as temperaturas médias dos estágios de cristalização são respectivamente $1228^{\circ} \mathrm{C}(\mathrm{P})$ e $1183^{\circ} \mathrm{C}(\mathrm{T})$ pelo método de Kudo e Weill (1970) e, $1225^{\circ} \mathrm{C}(\mathrm{P})$ e $1183^{\circ} \mathrm{C}(\mathrm{T})$ pelo método de Mathez (1973). O metabasito apresenta os seguintes valores de temperatura: $1159^{\circ} \mathrm{C}(\mathrm{P}) \mathrm{e}$ $1127^{\circ} \mathrm{C}(\mathrm{T})$ pelo método Kudo e Weill (1970) e $1161^{\circ} \mathrm{C}(\mathrm{P}) \mathrm{e}$ $1131^{\circ} \mathrm{C}(\mathrm{T})$ pelo método de Mathez (1973).

As temperaturas médias obtidas para os plagioclásios são relativamente um pouco mais elevadas em relação às temperaturas médias de cristalização dos piroxênios.

\section{Anfibólio}

A presença de anfibólio foi reconhecida nos três conjuntos de diques estudados. A Tabela 6 mostra as composições químicas dos grãos de anfibólios.

A classificação utilizada para os anfibólios está de acordo com as novas recomendações da IMA, segundo Leake et al. (1997), que apresenta uma nomenclatura mais simplificada que a anteriormente proposta (Leake, 1978).

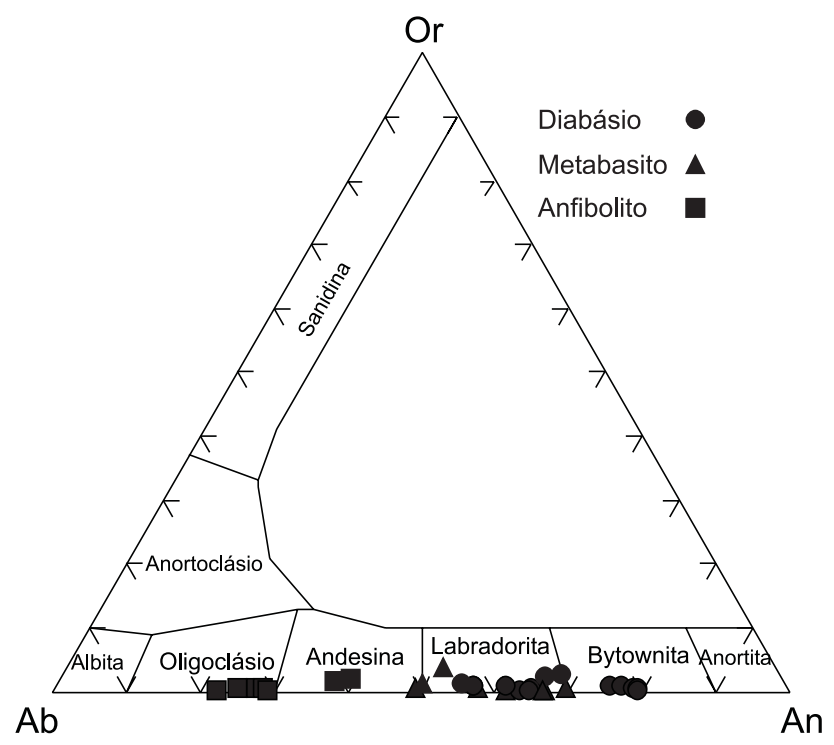

Figura 5. Variação composicional dos núcleos dos plagioclásios, segundo os componentes moleculares albita (Ab), anortita (An) e ortoclásio (Or) dos diques máficos de Goiás.
Para a estimativa de $\mathrm{Fe}^{+3}$, adotou-se o método de balanço de carga descrito por Robinson et al. (1981).

Todos os grãos de anfibólio são cálcicos, como pode ser observado na Figura 6. Ocorrem, porém, variações composicionais diversas relativas principalmente aos conteúdos de $\mathrm{Mg}$ e Fe. Para os três litotipos estudados, os anfibólios foram classificados em tschermakita, ferrotschermakita, magnésio-hornblenda, pargasita, ferropargasita, magnésio-hastingita, actinolita, ferro-actinolita e ferro-edenita (Figura 6).

\section{Minerais Opacos}

Os minerais opacos ocorrem nos três conjuntos de diques estudados. Suas microanálises químicas revelaram que não houve uma variação composicional significante entre os litotipos analisados, demonstrando a presença de magnetitas e ilmenitas. As análises químicas das magnetitas e ilmenitas encontram-se na Tabela 7.

Tabela 5. Temperatura dos plagioclásios e o seu valor médio para os diques de diabásio e metabasito. $\mathbf{N}$ - núcleo. B borda. $\mathbf{n}$ - número de amostras. $\mathbf{T}_{\text {Kudo e Weill }}$ - Temperatura Kudo e Weill (1970). $T_{\text {Mathez }}$ - Temperatura Mathez (1973).

\begin{tabular}{|c|c|c|c|c|}
\hline \multirow{2}{*}{\multicolumn{2}{|c|}{ Amostra }} & \multirow{2}{*}{ Fase } & \multicolumn{2}{|c|}{ Geotermômetros $\left({ }^{\circ} \mathrm{C}\right)$} \\
\hline & & & $T_{\text {Kudo e Weill }}$ & $T_{\text {Mathez }}$ \\
\hline \multirow{11}{*}{$\begin{array}{l}\frac{0}{0} \\
-\mathbb{0} \\
\frac{0}{0} \\
\frac{0}{0}\end{array}$} & \multirow{2}{*}{ CR01 } & $\mathrm{N}$ & 1189 & 1189 \\
\hline & & B & 1148 & 1151 \\
\hline & \multirow{2}{*}{ CR107 } & $\mathrm{N}$ & 1252 & 1248 \\
\hline & & B & 1154 & 1155 \\
\hline & \multirow{2}{*}{ GO07 } & $\mathrm{N}$ & 1284 & 1278 \\
\hline & & B & 1279 & 1273 \\
\hline & \multirow{2}{*}{ G0113 } & $\mathrm{N}$ & 1164 & 1165 \\
\hline & & $\mathrm{B}$ & 1152 & 1153 \\
\hline & CR110 & $\mathrm{N}$ & 1249 & 1245 \\
\hline & \multirow{2}{*}{ Média } & $N(n=5)$ & 1228 & 1225 \\
\hline & & $B(n=4)$ & 1183 & 1183 \\
\hline \multirow{9}{*}{ 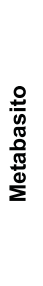 } & \multirow{2}{*}{ CR02 } & $\mathrm{N}$ & 1030 & 1041 \\
\hline & & B & 1094 & 1100 \\
\hline & CR09 & $\mathrm{N}$ & 1209 & 1207 \\
\hline & \multirow{2}{*}{ CR104 } & $\mathrm{N}$ & 1206 & 1204 \\
\hline & & $B$ & 1160 & 1162 \\
\hline & G013 & $\mathrm{N}$ & 1205 & 1203 \\
\hline & G0100 & $\mathrm{N}$ & 1145 & 1147 \\
\hline & \multirow{2}{*}{ Média } & $N(n=5)$ & 1159 & 1161 \\
\hline & & $B(n=2)$ & 1127 & 1131 \\
\hline
\end{tabular}


Tabela 6. Composição química, em \% de peso, dos anfibólios. Fórmula estrutural calculada com base em 23 átomos de oxigênio. Act - actinolita. Mghbl - magnésio-hornblenda. Fehbl - ferro-hornblenda. Tsch - tschermakita. FeTsch - ferro-tschermakita. Parg - pargasita. FeParg - ferro-pargasita. Eden - edenita. FeEden - ferro-edenita. FeAct - ferro-actinolita. MgHas - magnésio-hastingsita.

\begin{tabular}{|c|c|c|c|c|c|c|c|c|c|c|c|c|c|c|c|}
\hline Litotipo & & & & & & & & abásio & & & & & & & \\
\hline Amostra & CR01 & $\overline{\text { CR01 }}$ & CR107 & CR107 & CR107 & CR107 & CR107 & G005 & GO05 & G005 & GO05 & G006 & G006 & G006 & $\overline{G 006}$ \\
\hline $\mathrm{SiO}_{2}$ & 36,64 & 36,43 & 45,27 & 43,54 & 43,75 & 42,78 & 42,40 & 51,54 & 51,91 & 52,95 & 53,44 & 39,40 & 50,65 & 38,80 & 38,90 \\
\hline $\mathrm{TiO}_{2}$ & 0,89 & 1,26 & 1,07 & 1,31 & 1,26 & 2,38 & 1,08 & 0,05 & 0,46 & 0,46 & 0,35 & 0,19 & 1,58 & 0,35 & 0,25 \\
\hline $\mathrm{Al}_{2} \mathrm{O}_{3}$ & 17,98 & 16,46 & 10,58 & 12,22 & 12,15 & 10,84 & 12,73 & 2,12 & 2,73 & 2,60 & 2,32 & 17,70 & 1,72 & 20,24 & 20,93 \\
\hline $\mathrm{FeO}$ & 23,54 & 22,61 & 15,47 & 16,17 & 15,81 & 18,01 & 17,91 & 22,63 & 17,54 & 17,25 & 12,24 & 24,34 & 18,24 & 21,23 & 22,26 \\
\hline $\mathrm{MnO}$ & 0,12 & 0,10 & 0,06 & 0,07 & 0,12 & 0,11 & 0,03 & 0,23 & 0,18 & 0,15 & 0,10 & 0,26 & 0,33 & 0,26 & 0,12 \\
\hline $\mathrm{MgO}$ & 4,44 & 5,04 & 11,44 & 10,37 & 10,56 & 9,71 & 8,98 & 9,82 & 12,46 & 13,29 & 16,23 & 3,28 & 11,41 & 3,97 & 2,82 \\
\hline $\mathrm{CaO}$ & 11,51 & 11,49 & 11,88 & 11,57 & 11,66 & 11,07 & 11,39 & 11,66 & 12,13 & 11,56 & 12,89 & 11,01 & 15,58 & 11,22 & 11,06 \\
\hline $\mathrm{Na}_{2} \mathrm{O}$ & 1,33 & 1,43 & 1,50 & 1,72 & 1,58 & 1,30 & 1,58 & 0,38 & 0,32 & 0,34 & 0,26 & 1,33 & 0,25 & 1,57 & 1,38 \\
\hline $\mathrm{K}_{2} \mathrm{O}$ & 2,30 & 2,35 & 0,70 & 0,83 & 0,86 & 0,80 & 1,00 & 0,14 & 0,04 & 0,03 & 0,03 & 0,64 & 0,01 & 0,57 & 0,62 \\
\hline Total & 98,75 & 97,17 & 98,25 & 98,13 & 98,21 & 97,40 & 97,57 & 98,57 & 97,77 & 98,63 & 97,86 & 98,15 & 99,77 & 98,21 & 98,34 \\
\hline$\overline{\mathrm{Si}}$ & 5,63 & 5,70 & 6,67 & 6,47 & 6,49 & 6,44 & 6,40 & 7,67 & 7,61 & 7,65 & 7,64 & 6,01 & 7,49 & 5,85 & $\overline{5,88}$ \\
\hline $\mathrm{Al}^{\mathrm{IV}}$ & 2,37 & 2,30 & 1,33 & 1,53 & 1,51 & 1,56 & 1,60 & 0,33 & 0,39 & 0,36 & 0,36 & 1,99 & 0,30 & 2,15 & 2,12 \\
\hline Total & 8,00 & 8,00 & 8,00 & 8,00 & 8,00 & 8,00 & 8,00 & 8,00 & 8,00 & 8,00 & 8,00 & 8,00 & 8,05 & 8,00 & 8,00 \\
\hline$\overline{\mathrm{Al}^{\mathrm{VI}}}$ & 0,89 & 0,74 & 0,51 & 0,61 & 0,61 & 0,37 & 0,67 & 0,04 & 0,09 & 0,09 & 0,03 & 1,19 & 0,00 & 1,44 & 1,60 \\
\hline $\mathrm{Ti}$ & 0,10 & 0,15 & 0,12 & 0,15 & 0,14 & 0,27 & 0,12 & 0,01 & 0,05 & 0,05 & 0,04 & 0,02 & 0,09 & 0,04 & 0,03 \\
\hline $\mathrm{Fe}^{3}$ & 0,54 & 0,44 & 0,18 & 0,20 & 0,20 & 0,35 & 0,23 & 0,30 & 0,19 & 0,32 & 0,20 & 0,46 & 0,11 & 0,28 & 0,25 \\
\hline $\mathrm{Mg}$ & 1,02 & 1,18 & 2,52 & 2,30 & 2,34 & 2,18 & 2,02 & 2,18 & 2,73 & 2,86 & 3,46 & 0,75 & 2,52 & 0,89 & 0,64 \\
\hline $\mathrm{Fe}^{2}$ & 2,49 & 2,52 & 1,73 & 1,81 & 1,77 & 1,92 & 2,03 & 2,52 & 1,96 & 1,76 & 1,27 & 2,65 & 1,98 & 2,39 & 2,56 \\
\hline $\mathrm{Mn}$ & 0,02 & 0,01 & 0,01 & 0,01 & 0,02 & 0,01 & 0,00 & 0,03 & 0,02 & 0,02 & 0,01 & 0,03 & 0,04 & 0,03 & 0,02 \\
\hline Total & 5,05 & 5,03 & 5,06 & 5,07 & 5,07 & 5,10 & 5,07 & 5,06 & 5,04 & 5,10 & 5,00 & 5,10 & 4,73 & 5,08 & 5,09 \\
\hline$\overline{\mathrm{Ca}}$ & 1,90 & 1,93 & 1,88 & 1,84 & 1,85 & 1,79 & 1,84 & 1,86 & 1,91 & 1,79 & 1,97 & 1,80 & 2,26 & 1,81 & $\overline{1,79}$ \\
\hline $\mathrm{Na}$ & 0,40 & 0,43 & 0,43 & 0,50 & 0,46 & 0,38 & 0,46 & 0,11 & 0,09 & 0,10 & 0,07 & 0,39 & 0,07 & 0,46 & 0,40 \\
\hline $\mathrm{K}$ & 0,45 & 0,47 & 0,13 & 0,16 & 0,16 & 0,15 & 0,19 & 0,03 & 0,01 & 0,01 & 0,01 & 0,13 & 0,00 & 0,11 & 0,12 \\
\hline Total & 2,74 & 2,83 & 2,44 & 2,50 & 2,47 & 2,32 & 2,50 & 2,00 & 2,00 & 1,89 & 2,05 & 2,32 & 2,34 & 2,38 & 2,31 \\
\hline Nome & FeParg & FeParg & Mghbl & Parg & Parg & Mghb| & Parg & FeAct & Act & Act & Act & FeTsch & Mghbl & FeTsch & $\overline{\mathrm{FeTsch}}$ \\
\hline
\end{tabular}

\begin{tabular}{|c|c|c|c|c|c|c|c|c|c|}
\hline Litotipo & & & & & Diabásio & & & & \\
\hline Amostra & G007 & G007 & G007 & G007 & G007 & G007 & G007 & CR110 & CR110 \\
\hline $\mathrm{SiO}_{2}$ & 42,74 & 44,00 & 43,44 & 42,81 & 41,51 & 42,84 & 43,68 & 38,69 & 39,49 \\
\hline $\mathrm{TiO}_{2}$ & 2,67 & 2,36 & 2,53 & 2,48 & 1,18 & 2,76 & 2,39 & 0,14 & 0,13 \\
\hline $\mathrm{Al}_{2} \mathrm{O}_{3}$ & 10,39 & 9,67 & 10,02 & 10,79 & 14,63 & 10,34 & 9,21 & 19,41 & 19,28 \\
\hline $\mathrm{FeO}$ & 19,18 & 19,63 & 18,97 & 18,47 & 18,03 & 19,02 & 20,43 & 17,91 & 14,64 \\
\hline $\mathrm{MnO}$ & 0,23 & 0,27 & 0,21 & 0,26 & 0,22 & 0,21 & 0,30 & 0,27 & 0,16 \\
\hline $\mathrm{MgO}$ & 9,75 & 9,53 & 9,61 & 9,78 & 8,26 & 9,47 & 9,36 & 7,39 & 11,32 \\
\hline $\mathrm{CaO}$ & 10,64 & 10,71 & 10,59 & 10,53 & 11,35 & 10,66 & 10,67 & 10,24 & 11,11 \\
\hline $\mathrm{Na}_{2} \mathrm{O}$ & 2,32 & 1,83 & 2,14 & 1,88 & 1,98 & 2,06 & 1,75 & 2,51 & 2,80 \\
\hline $\mathrm{K}_{2} \mathrm{O}$ & 0,59 & 0,62 & 0,56 & 0,52 & 0,60 & 0,59 & 0,58 & 1,03 & 0,59 \\
\hline Total & 98,90 & 99,11 & 98,41 & 97,89 & 98,12 & 98,36 & 98,71 & 97,59 & 99,52 \\
\hline $\mathrm{Si}$ & 6,40 & 6,57 & 6,52 & 6,42 & 6,23 & 6,45 & 6,55 & 5,80 & 5,67 \\
\hline $\mathrm{Al}^{\mathrm{IV}}$ & 1,60 & 1,43 & 1,48 & 1,58 & 1,77 & 1,56 & 1,45 & 2,20 & 2,33 \\
\hline Total & 8,00 & 8,00 & 8,00 & 8,00 & 8,00 & 8,00 & 8,00 & 8,00 & 8,00 \\
\hline $\mathrm{Al}^{\mathrm{Vl}}$ & 0,23 & 0,27 & 0,29 & 0,33 & 0,81 & 0,28 & 0,17 & 1,22 & 0,93 \\
\hline $\mathrm{Ti}$ & 0,30 & 0,27 & 0,29 & 0,28 & 0,13 & 0,31 & 0,27 & 0,02 & 0,01 \\
\hline $\mathrm{Fe}^{3}$ & 0,39 & 0,38 & 0,34 & 0,44 & 0,24 & 0,35 & 0,45 & 0,49 & 0,80 \\
\hline $\mathrm{Mg}$ & 2,18 & 2,12 & 2,15 & 2,19 & 1,85 & 2,12 & 2,09 & 1,65 & 2,4 \\
\hline $\mathrm{Fe}^{2}$ & 2,01 & 2,07 & 2,04 & 1,88 & 2,02 & 2,04 & 2,11 & 1,75 & 0,95 \\
\hline $\mathrm{Mn}$ & 0,03 & 0,03 & 0,03 & 0,03 & 0,03 & 0,03 & 0,04 & 0,03 & 0,02 \\
\hline Total & 5,14 & 5,13 & 5,14 & 5,15 & 5,08 & 5,13 & 5,13 & 5,16 & 5,14 \\
\hline$\overline{\mathrm{Ca}}$ & 1,71 & 1,71 & 1,70 & 1,69 & 1,82 & 1,72 & 1,71 & 1,64 & 1,71 \\
\hline $\mathrm{Na}$ & 0,67 & 0,53 & 0,62 & 0,55 & 0,58 & 0,60 & 0,51 & 0,73 & 0,78 \\
\hline K & 0,11 & 0,12 & 0,11 & 0,10 & 0,12 & 0,11 & 0,11 & 0,20 & 0,11 \\
\hline Total & 2,49 & 2,36 & 2,43 & 2,34 & 2,52 & 2,43 & 2,33 & 2,57 & 2,60 \\
\hline Nome & $\mathrm{MgHas}$ & Mghbl & Eden & Mghbl & FeParg & MgHas & Mghbl & FeParg & Parg \\
\hline
\end{tabular}

(continua...) 
(Tabela 6 - Continuação)

\begin{tabular}{|c|c|c|c|c|c|c|c|c|c|c|c|c|c|c|c|c|c|c|c|}
\hline \multirow{2}{*}{$\begin{array}{l}\text { Litotipo } \\
\text { Amostra }\end{array}$} & \multicolumn{19}{|c|}{ Metabasito } \\
\hline & CR02 & CR02 & CR02 & CR02 & $\overline{\mathrm{CRO2}}$ & CR02 & CR09 & CR09 & CR09 & CR09 & CR09 & CR09 & CR104 & CR104 & CR104 & CR104 & G013 & G013 & G0100 \\
\hline$\overline{\mathrm{SiO}_{2}}$ & 44,14 & 41,59 & 43,74 & 41,45 & 42,66 & 41,24 & 41,90 & 48,35 & 49,47 & 52,95 & 41,28 & 43,15 & 46,42 & 45,77 & 44,86 & 45,01 & 39,99 & 51,76 & 49,81 \\
\hline $\mathrm{TiO}_{2}$ & 0,45 & 0,43 & 0,52 & 0,18 & 0,48 & 0,44 & 0,35 & 0,86 & 1,03 & 0,13 & 0,25 & 0,34 & 0,32 & 0,77 & 0,98 & 0,97 & 0,17 & 0,60 & 2,29 \\
\hline $\mathrm{Al}_{2} \mathrm{O}_{3}$ & 14,63 & 17,44 & 16,90 & 17,60 & 16,70 & 18,31 & 17,35 & 8,99 & 7,27 & 5,02 & 17,99 & 15,80 & 9,97 & 8,18 & 9,08 & 9,14 & 18,99 & 2,03 & 1,99 \\
\hline $\mathrm{FeO}$ & 15,60 & 16,83 & 16,19 & 16,79 & 16,40 & 17,21 & 17,65 & 16,33 & 15,29 & 13,16 & 17,93 & 17,74 & 14,61 & 22,01 & 21,04 & 21,19 & 19,71 & 16,40 & 20,76 \\
\hline $\mathrm{MnO}$ & 0,29 & 0,31 & 0,29 & 0,28 & 0,22 & 0,26 & 0,17 & 0,22 & 0,29 & 0,25 & 0,16 & 0,24 & 0,14 & 0,16 & 0,13 & 0,16 & 0,35 & 0,12 & 0,23 \\
\hline $\mathrm{MgO}$ & 9,58 & 7,79 & 8,66 & 8,45 & 8,55 & 7,66 & 7,38 & 11,73 & 12,61 & 14,96 & 7,02 & 8,49 & 11,94 & 9,88 & 9,34 & 9,34 & 4,26 & 13,33 & 11,44 \\
\hline $\mathrm{CaO}$ & 12,19 & 11,99 & 11,44 & 11,72 & 12,20 & 11,94 & 11,88 & 11,58 & 11,72 & 12,46 & 11,86 & 11,96 & 12,88 & 9,14 & 10,48 & 9,77 & 10,77 & 12,06 & 10,69 \\
\hline $\mathrm{K}_{2} \mathrm{O}$ & 0,42 & 0,71 & 0,43 & 0,45 & 0,48 & 0,55 & 0,63 & 0,55 & 0,28 & 0,10 & 0,77 & 0,53 & 0,44 & 0,42 & 0,51 & 0,48 & 0,56 & 0,07 & 0,03 \\
\hline Total & 98,51 & 98,43 & 99,30 & 98,50 & 98,83 & 98,94 & 98,70 & 99,51 & 98,72 & 99,50 & 98,71 & 99,49 & 98,06 & 97,89 & 98,14 & 97,80 & 96,27 & 96,52 & 97,53 \\
\hline$\overline{\mathrm{Si}}$ & 6,44 & 6,14 & 6,32 & 6,08 & 6,23 & 6,04 & 6,18 & 6,96 & 7,14 & 7,47 & 6,11 & 6,28 & 6,81 & 6,80 & 6,71 & 6,73 & 6,12 & 7,65 & 7,40 \\
\hline $\mathrm{Al}^{\mathrm{IV}}$ & 1,56 & 1,86 & 1,68 & 1,93 & 1,77 & 1,96 & 1,82 & 1,04 & 0,86 & 0,53 & 1,90 & 1,72 & 1,19 & 1,20 & 1,29 & 1,27 & 1,88 & 0,34 & 0,35 \\
\hline Total & 8,00 & 8,00 & 8,00 & 8,00 & 8,00 & 8,00 & 8,00 & 8,00 & 8,00 & 8,00 & 8,00 & 8,00 & 8,00 & 8,00 & 8,00 & 8,00 & 8,00 & 8,00 & 8,09 \\
\hline$\overline{\mathrm{Al}^{\mathrm{VI}}}$ & 0,96 & 1,17 & 1,19 & 1,11 & 1,10 & 1,20 & 1,20 & 0,49 & 0,38 & 0,31 & 1,24 & 0,99 & 0,53 & 0,23 & 0,31 & 0,34 & 1,55 & 0,01 & 0,00 \\
\hline $\mathrm{Ti}$ & 0,05 & 0,05 & 0,06 & 0,02 & 0,05 & 0,05 & 0,04 & 0,09 & 0,11 & 0,01 & 0,03 & 0,04 & 0,04 & 0,09 & 0,11 & 0,11 & 0,02 & 0,07 & 0,13 \\
\hline $\mathrm{Fe}^{3}$ & 0,17 & 0,19 & 0,30 & 0,41 & 0,25 & 0,32 & 0,18 & 0,29 & 0,25 & 0,18 & 0,18 & 0,34 & 0,11 & 0,94 & 0,61 & 0,68 & 0,19 & 0,25 & 0,36 \\
\hline $\mathrm{Fe}^{2}$ & 1,74 & 1,89 & 1,66 & 1,65 & 1,75 & 1,79 & 2,00 & 1,68 & 1,60 & 1,38 & 2,04 & 1,82 & 1,69 & 1,79 & 2,02 & 1,97 & 2,34 & 1,76 & 2,01 \\
\hline $\mathrm{Mn}$ & 0,04 & 0,04 & 0,04 & 0,03 & 0,03 & 0,03 & 0,02 & 0,03 & 0,04 & 0,03 & 0,02 & 0,03 & 0,02 & 0,02 & 0,02 & 0,02 & 0,05 & 0,02 & 0,03 \\
\hline Total & 5,03 & 5,05 & 5,10 & 5,07 & 5,04 & 5,06 & 5,06 & 5,10 & 5,09 & 5,06 & 5,05 & 5,06 & 4,99 & 5,26 & 5,15 & 5,21 & 5,11 & 5,04 & 5,05 \\
\hline$\overline{\mathrm{Ca}}$ & 1,91 & 1,90 & 1,77 & 1,84 & 1,91 & 1,87 & 1,88 & 1,79 & 1,81 & 1,88 & 1,88 & 1,87 & 2,01 & 1,46 & 1,68 & 1,57 & 1,77 & 1,91 & 1,70 \\
\hline $\mathrm{Na}$ & 0,34 & 0,38 & 0,32 & 0,45 & 0,32 & 0,38 & 0,40 & 0,25 & 0,21 & 0,13 & 0,42 & 0,35 & 0,37 & 0,35 & 0,39 & 0,41 & 0,44 & 0,04 & 0,08 \\
\hline $\mathrm{K}$ & 0,08 & 0,13 & 0,08 & 0,08 & 0,09 & 0,10 & 0,12 & 0,10 & 0,05 & 0,02 & 0,15 & 0,10 & 0,08 & 0,08 & 0,10 & 0,09 & 0,11 & 0,01 & 0,01 \\
\hline Total & 2,33 & 2,41 & 2,17 & 2,37 & 2,32 & 2,35 & 2,39 & 2,14 & 2,08 & 2,03 & 2,44 & 2,32 & 2,46 & 1,89 & 2,17 & 2,07 & 2,31 & 1,97 & 1,79 \\
\hline Nome & Mghbl & FeTsch & Mghbl & Tsch & Tsch & FeTsch & FeTsch & Mghbl & Mghbl & Mghbl & FeTsch & Fehbl & Mghbl & Mghbl & Mghbl & Mghbl & FeTsch & Act & Mghbl \\
\hline
\end{tabular}

\begin{tabular}{lrrrrrrrrr}
\hline Litotipo & \multicolumn{10}{c}{ Anfibolito } \\
\hline Amostra & CR105 & CR105 & CR105 & CR105 & CR105 & G0101 & G0101 & G0101 & G0101 \\
\hline $\mathrm{SiO}_{2}$ & 44,07 & 42,99 & 42,48 & 45,73 & 44,28 & 40,82 & 38,44 & 44,76 & 37,22 \\
$\mathrm{TiO}_{2}$ & 0,41 & 0,50 & 0,37 & 0,45 & 0,58 & 2,09 & 0,43 & 0,25 & 0,43 \\
$\mathrm{Al}_{2} \mathrm{O}_{3}$ & 15,05 & 16,01 & 16,86 & 13,13 & 14,67 & 10,22 & 14,62 & 15,73 & 14,78 \\
$\mathrm{FeO}$ & 14,31 & 15,30 & 15,44 & 14,32 & 14,45 & 21,23 & 23,49 & 18,06 & 23,43 \\
$\mathrm{MnO}$ & 0,24 & 0,28 & 0,24 & 0,22 & 0,28 & 0,29 & 0,32 & 0,17 & 0,27 \\
$\mathrm{MgO}$ & 10,33 & 9,60 & 9,28 & 11,32 & 10,36 & 6,80 & 4,90 & 4,08 & 4,72 \\
$\mathrm{CaO}$ & 11,69 & 11,78 & 11,88 & 12,11 & 11,92 & 11,12 & 11,19 & 11,22 & 11,17 \\
$\mathrm{Na}{ }_{2} \mathrm{O}$ & 1,46 & 1,49 & 1,48 & 1,23 & 1,32 & 1,15 & 1,65 & 1,55 & 1,74 \\
$\mathrm{~K}_{2} \mathrm{O}$ & 0,39 & 0,48 & 0,49 & 0,31 & 0,38 & 1,79 & 1,87 & 1,35 & 1,79 \\
$\mathrm{Total}$ & 98,07 & 98,59 & 98,82 & 98,95 & 98,33 & 98,00 & 99,35 & 98,90 & 97,79 \\
\hline $\mathrm{Si}$ & 6,43 & 6,28 & 6,20 & 6,59 & 6,45 & 6,45 & 6,03 & 6,90 & 5,94 \\
$\mathrm{Al}{ }^{\mathrm{IV}}$ & 1,57 & 1,72 & 1,80 & 1,41 & 1,55 & 1,55 & 1,97 & 1,10 & 2,07 \\
$\mathrm{Total}$ & 8,00 & 8,00 & 8,00 & 8,00 & 8,00 & 8,00 & 8,00 & 8,00 & 8,00 \\
\hline $\mathrm{Al} \mathrm{VI}^{\mathrm{V}}$ & 1,01 & 1,03 & 1,09 & 0,82 & 0,96 & 0,36 & 0,73 & 1,75 & 0,71 \\
$\mathrm{Ti}$ & 0,05 & 0,06 & 0,04 & 0,05 & 0,06 & 0,25 & 0,05 & 0,03 & 0,05 \\
$\mathrm{Fe}{ }^{3}$ & 0,23 & 0,25 & 0,27 & 0,22 & 0,20 & 0,15 & 0,38 & 0,00 & 0,45 \\
$\mathrm{Mg}$ & 2,25 & 2,09 & 2,02 & 2,43 & 2,25 & 1,60 & 1,15 & 0,94 & 1,12 \\
$\mathrm{Fe}{ }^{2}$ & 1,52 & 1,62 & 1,61 & 1,51 & 1,56 & 2,66 & 2,70 & 2,33 & 2,68 \\
$\mathrm{Mn}$ & 0,03 & 0,03 & 0,03 & 0,03 & 0,03 & 0,04 & 0,04 & 0,03 & 0,04 \\
$\mathrm{Total}$ & 5,08 & 5,07 & 5,07 & 5,06 & 5,07 & 5,05 & 5,05 & 5,00 & 5,04 \\
\hline $\mathrm{Ca}$ & 1,83 & 1,84 & 1,86 & 1,87 & 1,86 & 1,88 & 1,88 & 1,85 & 1,91 \\
$\mathrm{Na}$ & 0,41 & 0,42 & 0,42 & 0,35 & 0,37 & 0,35 & 0,50 & 0,46 & 0,54 \\
$\mathrm{~K}$ & 0,07 & 0,09 & 0,09 & 0,06 & 0,07 & 0,36 & 0,38 & 0,27 & 0,37 \\
Total & 2,31 & 2,35 & 2,37 & 2,27 & 2,30 & 2,60 & 2,76 & 2,58 & 2,81 \\
\hline $\mathrm{Nome}$ & $\mathrm{Mghbl}$ & $\mathrm{Mghbl}$ & $\mathrm{Tsch}$ & $\mathrm{Mghbl}$ & $\mathrm{Mghbl}$ & $\mathrm{FeParg}$ & $\mathrm{FeParg}$ & $\mathrm{FeEden}$ & $\mathrm{FeParg}$ \\
\hline & & & & & & & & &
\end{tabular}


(A)

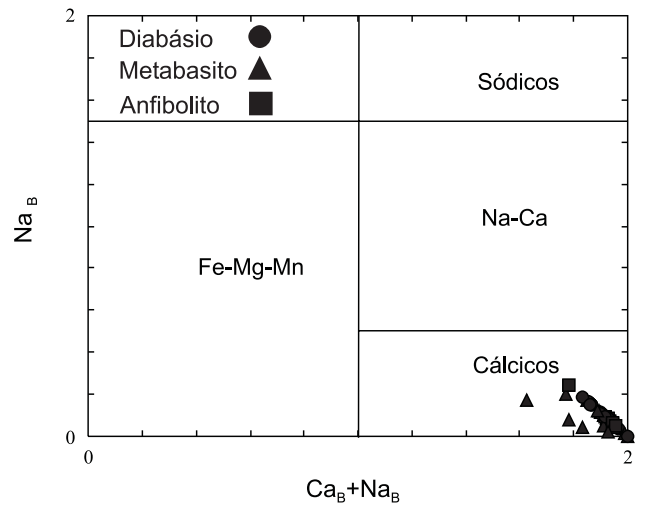

(C)

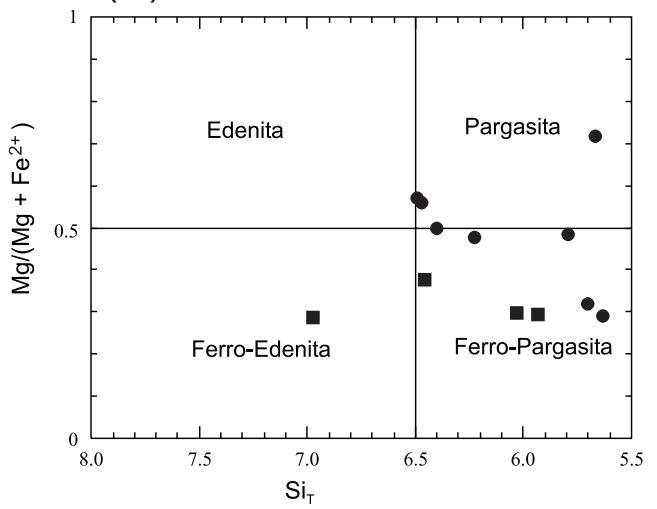

(B)

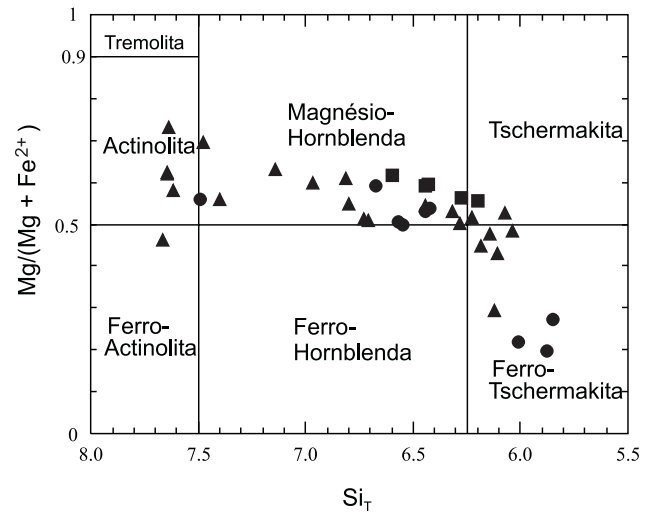

(D)

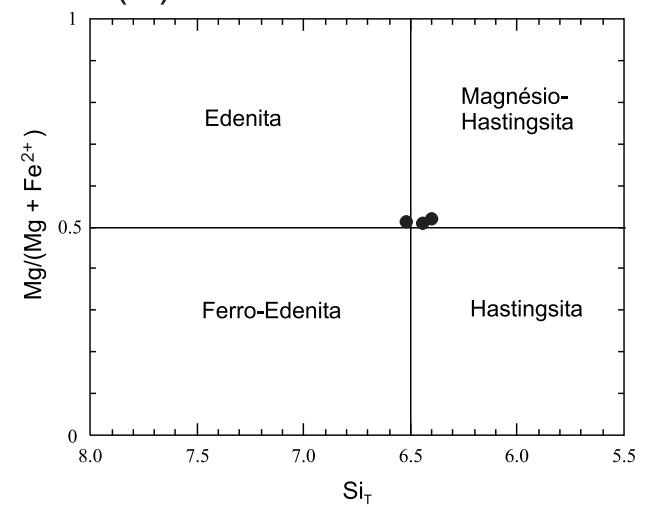

Figura 6. Diagramas classificatórios segundo Leake et al. (1997) para os anfibólios cálcicos: A - Classificação geral dos quatros principais grupos de anfibólios.

$\mathrm{B}-\left(\mathrm{Ca}_{\mathrm{B}} \geq 1,5 ;(\mathrm{Na}+\mathrm{K})_{\mathrm{A}}<0,5\right.$ e $\left.\mathrm{Ti}<0,5\right)$.

$\mathrm{C}-\left(\mathrm{Ca}_{\mathrm{B}} \geq 1,5 ;(\mathrm{Na}+\mathrm{K})_{\mathrm{A}} \geq 0,5 ; \mathrm{Ti}<0,5\right.$ e $\left.\mathrm{Al}_{\mathrm{C}} \geq \mathrm{Fe}^{3+}\right)$.

$\mathrm{D}-\left(\mathrm{Ca}_{\mathrm{B}} \geq 1,5 ;(\mathrm{Na}+\mathrm{K})_{\mathrm{A}} \geq 0,5 ; \mathrm{Ti}<0,5\right.$ e $\left.\mathrm{Al}_{\mathrm{C}}<\mathrm{Fe}^{3+}\right)$.

Tabela 7. Composição química, em \% de peso, das magnetitas e ilmenitas. $\mathrm{FeO}$ e $\mathrm{Fe}_{2} \mathrm{O}_{3}$ foram calculados segundo Carmichael (1967).

\begin{tabular}{|c|c|c|c|c|c|c|c|c|c|c|c|c|c|c|c|c|c|}
\hline \multirow{2}{*}{$\begin{array}{l}\text { Litotipo } \\
\text { Amostra }\end{array}$} & \multicolumn{7}{|c|}{ Diabásio } & \multicolumn{6}{|c|}{ Metabasito } & \multicolumn{4}{|c|}{ Anfibolito } \\
\hline & G006 & G007 & G007 & GO07 & G007 & G0113 & G0113 & CR104 & CR104 & CR104 & CR104 & CR104 & G0100 & CR105 & CR105 & G0101 & G0101 \\
\hline$\overline{\mathrm{SiO}_{2}}$ & 0,16 & 0,08 & 0,06 & 0,07 & 0,02 & 1,19 & 0,06 & 0,04 & 0,02 & 0,00 & 0,01 & 0,05 & 0,04 & 0,01 & 0,03 & 0,06 & $\overline{0,04}$ \\
\hline $\mathrm{TiO}_{2}$ & 5,90 & 0,71 & 0,83 & 50,59 & 51,52 & 18,75 & 18,07 & 48,06 & 51,43 & 50,30 & 49,53 & 1,45 & 50,87 & 0,01 & 0,03 & 50,26 & 50,54 \\
\hline $\mathrm{Al}_{2} \mathrm{O}_{3}$ & 0,75 & 0,38 & 0,32 & 0,03 & 0,00 & 1,41 & 1,45 & 0,19 & 0,02 & 0,02 & 0,00 & 0,41 & 0,01 & 0,01 & 0,01 & 0,01 & 0,00 \\
\hline $\mathrm{FeO}$ & 36,90 & 30,94 & 30,96 & 44,12 & 44,91 & 16,96 & 15,38 & 42,39 & 44,91 & 43,90 & 43,11 & 31,31 & 44,98 & 24,83 & 24,78 & 42,89 & 43,25 \\
\hline $\mathrm{Fe}_{2} \mathrm{O}_{3}$ & 57,23 & 65,21 & 64,84 & 2,67 & 1,02 & 58,13 & 63,04 & 6,05 & 0,79 & 2,30 & 2,59 & 62,98 & 0,81 & 55,26 & 55,15 & 0,93 & 1,14 \\
\hline $\mathrm{MnO}$ & 0,20 & 0,01 & 0,02 & 0,70 & 0,74 & 0,93 & 0,94 & 0,31 & 0,72 & 0,70 & 0,77 & 0,00 & 0,78 & 0,02 & 0,00 & 1,88 & 1,86 \\
\hline $\mathrm{MgO}$ & 0,12 & 0,04 & 0,00 & 0,42 & 0,42 & 0,23 & 0,01 & 0,30 & 0,35 & 0,35 & 0,36 & 0,02 & 0,06 & 0,00 & 0,01 & 0,23 & 0,24 \\
\hline $\mathrm{ZnO}$ & 0,00 & 0,00 & 0,00 & 0,00 & 0,00 & 0,24 & 0,21 & 0,07 & 0,02 & 0,00 & 0,03 & 0,00 & 0,01 & 0,04 & 0,00 & 0,08 & 0,00 \\
\hline Total & 101,33 & 97,38 & 97,03 & 98,74 & 98,67 & 97,99 & 99,19 & 97,43 & 98,30 & 97,66 & 96,47 & 96,22 & 97,58 & 80,25 & 80,01 & 96,39 & 97,14 \\
\hline $\mathrm{FeOt}$ & 88,41 & 89,63 & 89,31 & 46,52 & 45,82 & 69,33 & 72,17 & 47,84 & 45,62 & 45,97 & 45,45 & 88,00 & 45,71 & 74,57 & 74,42 & 43,73 & 44,28 \\
\hline
\end{tabular}




\section{CONSIDERAÇÕES FINAIS}

O enxame de diques existente na região de Crixás-Goiás é quimicamente constituído por basalto e basalto andesítico toleítico. Petrograficamente tais corpos foram classificados em três grupos: diabásio, metabasito e anfibolito. Diques de diabásio ofíticos e subofíticos são constituídos essencialmente por plagioclásio, orto e clinopiroxênio, e anfibólio primário em pequena quantidade. Nos metabasitos os processos deutéricos/hidrotermais originaram grande quantidade de anfibólio a partir de piroxênio sem alterações texturais. Anfibolitos granoblásticos e nematoblásticos são constituídos essencialmente por anfibólio, plagioclásio e quartzo. Minerais acessórios são comuns aos três litotipos. Os diques de diabásio têm cerca de 2,4 Ga. Dados de campo, mineralógicos, texturais e geotermométricos indicam que diabásio e metabasito são consangüíneos, sendo estes produtos deutéricos/hidrotermais daqueles. É possível que os anfibolitos, em parte ou totalmente, tenham se originado dessa suíte magmática.

Os dados das composições químicas do piroxênio permitiram classificá-los em augita, pigeonita e enstatita, com tendências químicas típicas de suítes toleíticas. Os plagioclásios variam de labradorita a bytownita no diabásio e metabasito e, andesina a oligoclásio no anfibolito. Os anfibólios foram classificados em tschermakita, ferrotschermakita, magnásio-hornblenda, pargasita, ferropargasita, magnésio-hastingita, actinolita, ferro-actinolita e ferro-edenita. Geotermômetros de piroxênios e plagioclásios indicam que as temperaturas de cristalização foram da ordem de $1100^{\circ} \mathrm{Ca} 1200^{\circ} \mathrm{C}$.

\section{AGRADECIMENTOS}

Os autores expressam seus agradecimentos à FAPESP, ao CNPq e à CAPES pelos incentivos financeiros e aos laboratórios microscopia óptica e microssonda eletrônica do IGc/USP pela realização das análises. Agradecemos também a Profa. Dra. A. B. Menezes Leal e ao revisor anônimo pelos comentários construtivos.

\section{REFERÊNCIAS BIBLIOGRÁFICAS}

ALMEIDA, F. F. M.; HASUI, Y.; NEVES, B. B. B.; FUCK, R. A. Províncias estruturais brasileiras. In: SIMPÓSIO DE GEOLOGIA DO NORDESTE, 8., 1977. Campina Grande. Atas... Recife: SBG, 1977. p. 363-391.

ANDERSEN, D. J.; LINDSLEY, D. H.; DAVIDSON, P. M. Quilf version 6.42: a PASCAL program to assess equilibria among Fe_Mg_Ti oxides, pyroxenes, olivine, and quartz 1998.

BARD, J. P. Microtextures of igneous and metamorphic rocks. Dordrecht; Boston: D. Reidel, 1986. 264p.

BELLIENI, G.; PICCIRILLO, E. M.; PETRINI, R.; GIRARDI, V.A. V.; MENEZES LEAL, A. B.; TEIXEIRA, W.; BASTOS LEAL, L. R.; DEMIN, A.; COMINCHIARAMONTI, P.; TANNER DE OLIVEIRA, M. A. F. Petrological and Sr-Nd evidence bearing on Early Proterozoic magmatic events of the subcontinental mantle: São Francisco Craton (Uauá, NE-Brasil). Contributions to Mineralogy and Petrology, Berlin, v. 122, p. 252-261, 1995.

BOSSI, J.; CAMPAL, N.; CIVETTA, L.; DEMARCHI, G.; GIRARDI, V.A. V.; MAZZUCCHELLI, M.; NEGRINI,L.; RIVALENTI, G.; FRAGOSO CESAR, A. R. S.; SINIGOI, S.; TEIXEIRA, W.; PICCIRILLO, E. M.; MOLESINI, M. Early Proterozoic dike swarms from western Uruguay: geochemistry, Sr-Nd isotopes and petrogenesis. Chemical Geology, Amsterdam, v. 106, p. 263-277, 1993.

BROWN, G. M. Pyroxenes from the early and middle stages of fractionation of the Skaergaard intrusion, East Greenland. Mineralogical Magazine, London, v. 31, p. 511-543, 1957.

BROWN, G. M.; VINCENT, E. A. Pyroxenes from the late stages of fractionation of the Skaergaard intrusion, East Greenland. Journal of Petrology, London, v. 4, part 2, p. 175-197, 1963.

CARMICHAEL, I. S. E. The iron-Titanium oxides of sialic volcanic rocks and their associated ferromagnesium silicates. Contributions to Mineralogy of Petrology, Berlin, v. 14, p. 36-64, 1967.

CAWTHORN, R. G.; COLLERSON, K. D. The recalculation of pyroxene end member parameters and the estimation of ferrous and ferric iron content from electron microprobe analyses. American Mineralogist, Lancaster, v. 59, p. 1203-1208, 1974.

CONDIE, K. C.; BOBROW, D. J.; CARD, K. D. Geochemistry of Precambrian Mafic Dyke from Southern Superior Province. In: HALLS, H. C.; FAHRIG, W. F. (Ed.). Mafic Dykes Swarms. St John's : Geological Association of Canadá, 1987. p. 95-108. (Geol. Assoc. of Canada Special Paper, v. 34)

CORREAADA COSTA, P. C.; GIRARDI, V. A.V.; TEIXEIRA, W. Petrologia dos diques máficos da região de Crixás Goiás, porção Centro-Oeste do Estado de Goiás. In: CONGRESSO BRASILEIRO DE GEOLOGIA, 41., 2002. João Pessoa. Anais... João Pessoa: SBG, 1977. p 418.

CORRÊADACOSTA, P. C.; GIRARDI, V.A. V.; TEIXEIRA, W. Geoquímica isotópica (Sr e Nd) e geocronologia Rb/ $\mathrm{Sr}-{ }^{40} \mathrm{Ar} /{ }^{39} \mathrm{Ar}$ dos Diques Máficos de Goiás. In: CONGRESSO BRASILEIRO DE GEOQUÍMICA, 9., 2003. Belém. Resumos Expandidos... Belém: SBGq, 2003. p. 417. CORRÊA DA COSTA, P. C. Petrologia, Geoquímica e Geocronologia dos diques máficos da região de CrixásGoiás, porção centro-oeste do Estado de Goiás. 2003. 
151p. Tese (Doutorado) - Instituto de Geociências, Universidade de São Paulo, São Paulo.

CORRÊAGOMES, L. C.; TANNER DE OLIVEIRA, M.A. F; MOTTA, C. A.; CRUZ, M. J. M. Província de diques máficos do Estado da Bahia: mapas, estágio atual do conhecimento e evolução temporal. Salvador: UFBa, 1996. 114p.

CORRÊA GOMES, L. C.; SOUZA, M. N.; CORREIA, D. R. Feições estruturais de diques máficos - exemplos da Faixa Atlântica do Estado da Bahia. In: WORKSHOP DE DIQUES MÁFICOS PRECAMBRIANOS DO BRASIL, 1998. São Paulo. Boletim especial.... São Paulo: IUGS, 1989. Projeto PIGG-257, p. 16-21.

CORREIA, C. T.; GIRARDI, V.A. V.; TASSINARI, C. C. G; JOST, H. Rb-Sr and Sm-Nd geochronology of the Cana Brava layered mafic-ultramafic intrusion, Brazil, and considerations regarding its tectonic evolution. Revista Brasileira de Geociências, São Paulo, v. 27, p. 163-168, 1997.

DEER, W. A.; HOWIE, R. A.; ZUSSMAN, J. An introduction to the rock-forming minerals. 2. ed. Harlow, Essex; New York: Longman Scientific \& Technical: Wiley, 1992. 696p.

GIRARDI, V.A. V.; RIVALENTI, G.; SIENA, F.; SINIGOI, S. Precambrian Barro Alto Complex of Goias, Brasil: bulk geochemistry and phase equilibria. Neues Jahrbuch fur Mineralogie. Abhandlungen, v. 142, p. 270-291, 1981.

GIRARDI, V.A. V.; RIVALENTI, G.; SINIGOI, S. The petrogenesis of the Niquelandia layered basic-ultrabasic complex, Central Goias, Brazil. Journal of Petrology, London, v. 27, p. 715-744, 1986.

GIRARDI, V.A. V.; MAZZUCCHELLI, M.; MOLESINI, M.; FINATTI, M. C.; RIVALENTI, G.; CORREIA, C. T. Petrological and geochemical aspects of mafic dykes of Goias State, Brazil. In: CONGRESSO BRASILEIRO DE GEOLOGIA, 37., 1992. São Paulo. Anais... São Paulo: SBG, 1992. v. 1, p. 490-495.

HASUI, Y.; ALMEIDA, F. F. M. A. Geocronologia do Centro-Oeste Brasileiro. Boletim da Sociedade Brasileira de Geologia, São Paulo, v. 19, n. 1, p. 5-26, 1970.

IACUMIN, M.; PICCIRILLO, E. M.; GIRARDI, V. A. V.; TEIXEIRA, W.; BELLIENI, G.; ECHEVESTE, H.; FERNANDEZ, R.; PINESE, J. P. P.; RIBOT, A. Early proterozoic calc-alkaline and middle proterozoic tholeiitic dike swarms from Central-Eastern Argentina: petrology, geochemistry, Sr-Nd isotopes and tectonic implications. Journal of Petrology, London, v. 42, p. 2109-2143, 2001.

IACUMIN, M.; DE MIN, A.; PICCIRILLO, E. M.; BELLIENI, G. Source mantle heterogeneity and its role in the genesis of Late Archaean-Proterozoic (2.7-1.0 Ga) and Mesozoic (200 and 130 Ma) tholeitic magmatism in the South American Platform. Earth-Science Reviews, Amsterdam, v. 62, p. 365-397, 2003.

IRVINE, I. N.; BARAGAR, W. R. A. A guide to the chemical classification of the common volcanic rocks. Canadian Journal Earth Science, Ottawa, v. 8, p. 523-548, 1971.

ISHII, T. The relations between temperature and composition of pigeonites in some lavas and their application to geothermometry. Mineralogical Journal, Sapporo, v. 8, p. 48-57, 1975.

JOST, H.; CARMELO, A. C.; MENESES, P. R. Litologias, relações de contato e estrutura do Bloco Caiamar, Crixás, Goiás. In: SIMPÓSIODE GEOLOGIADOCENTRO-OESTE, 4., 1994. Brasília. Anais... Brasília: SBG, 1994. p. 18-20.

KRETZ, R. Transfer and exchange equilibria in a portion of the pyroxene quadrilateral as deduced from natural and experimental data. Geochemical et Cosmochimica Acta, St. Louis, v. 46, p. 411-421, 1982.

KUDO, A. M.; WEILL, D. F. An igneous plagioclase geotermometer. Contributions to Mineralogy and Petrology, Berlin, v. 25, p. 52-65, 1970.

KUYUMJIAN, R. M. Mafic dyke swarms in Goias, central, Brazil. In: CONGRESSO BRASILEIRO DE GEOQUÍMICA, 3; INTERNATIONALSYMPOSIUMON MAFIC DYKES, 1991. São Paulo. Extended abstracts... São Paulo: SBGq, 1991.p. 51-54.

KUYUMJIAN, R. M. Mafic Dyke swarms of the Goias Massif, Central Brazil. Revista Brasileira de Geociências, São Paulo, v. 28, n. 1, p. 45-50, 1998.

LE BAS, M. J.; LE MAITRE, R. W.; STRECKEISEN, A.; ZANETTIN, B. A chemical classification of volcanic rocks based on total alkali-silica diagram. Journal of Petrology, London, v. 27, p. 745-750, 1986.

LEAKE, B. E. Nomenclature of amphiboles. American Mineralogist, Lancaster, v. 63, p. 1023-1052, 1978.

LEAKE, B. E.; SCHUMACHER, J. C.; SMITH, D. C.; UNGARETTI, L.; WHITTAKER, E. J. W.; YOUZHI, G. Nomenclature of amphiboles. European Journal of Mineralogy, Sttutgart, v. 9, p. 623-651, 1997.

MATHEZ, E. A. Refinement of the Kudo-Weill plagioclase thermometer and its application to basaltic rocks. Contributions to Mineralogy and Petrology, Berlin, v. 41, p. 61-72, 1973.

MAZZUCCHELLI, M.; RIVALENTI, G.; PICCIRILLO, E.; GIRARDI, V. A. V.; CIVETTA, L. Petrology of the Proterozoic mafic dyke swarms of Uruguay and constraints on their mantle source composition. Precambrian Research, Amsterdam, v. 74, p. 177-194, 1995.

MAZZUCCHELLI, M.; RIVALENTI, MENEZES LEAL, A. B.; GIRARDI, V.A. V.; BRITO NEVES, B. B.; TEIXEIRA, W. Petrology of metabasaltic dykes in the Diamantina region, Minas Gerais, Brazil. Periodico di Mineralogia, Roma, v. 70, p. 231-254, 2000. 
MENEZES LEALA. B.; BELLIENI G.; GIRARDI V. A. V.; BASTOS LEAL, L. R.; TEIXEIRAW.; PICCIRILLOE. M. Contribuição ao estudo petrológico e geoquímico dos enxames de diques máficos de Uauá, Bahia, Brasil. Geochimica Brasiliensis, Rio de Janeiro, v. 9, n. 1, p. 61-90, 1995.

MENEZES LEAL,A. B.; GIRARDI, V.A. V.; BASTOS LEAL, L. R. Petrologia e geoquímica do magmatismo básico da Suíte Básica Apoteri, Estado de Roraima - Brasil. Geochimica Brasiliensis, Rio de Janeiro, v. 14, p. $155-174,2000$.

MORIMOTO, N. Nomenclature of pyroxenes. American Mineralogist, Lancaster, v. 73, p. 1123-1133, 1988.

PIMENTEL, M. M.; WHITEHOUSE, M. J.; VIANA, M. DAS G.; FUCK, R. A.; MACHADO, N. The Mara Rosa Arc in the Tocantins Province: further evidence for Neoproterozoic crustal accretion in Central Brazil. Precambrian Research, Amsterdam, v. 81, p. 299-310, 1997.

PIMENTEL, M. M; JOST, H.; FUCK, R. A.; ARMSTRONG, R. A.; DANTAS, E. L.; PORTREL, A. Neoproterozoic anatexis of $2.9 \mathrm{Ga}$ old granitoids in the Goiás-Crixás Archean Block, Central Brazil: evidence from new U-Pb shrimp data and Sm-Nd isotopes. Revista Brasileira de Geociências, São Paulo. (submetido).

PINESE, J. P. P. Geoquímica, geologia isotópica e aspectos petrológicos dos diques máficos pré-cambrianos da Região de Lavras (MG), porção sul do Cráton São Francisco. 1997. 178f. Tese (Doutorado) - Instituto de Geociências, Universidade de São Paulo, São Paulo.

QUEIROZ, C. L. Evolução tectono-estrutural dos terrenos granito-greenstone belts de Crixás, Brasil central. 2000. Tese (Doutorado) - Instituto de Geociências, Universidade de Brasília, Brasília.

RICHARD, L. R.; CLARKE, D. Amphibol: a program for calculating structural formulae and for classifying and plotting analyses of Amphiboles. American Mineralogist, Lancaster, v. 75, p. 421-423, 1990.

RICHARD, L. R. Mineralogical and petrological data processing system. Minpet for Windows, version 2.02. MinPet Geological Software, Canada, 1995.

ROBINSON, P.; SPEAR, F. S.; SCHUMACHER, J. C.; LAIRD, J.; KLEIN, C.; EVANS, B. W.; DOOLAN, B. L. Phase relations of metamorfic amphiboles: natural ocurrence and theory. Reviews in Mineralogy, Washington, v. 9B, p. 1-228, 1981.

TARNEY, J. Geochemistry and significance of mafic dyke swarms in the Proterozoic. In: Condie, K. C. (Ed). Proterozoic crustal evolution. Amsterdam; New York: Elsevier, p. 151-179, 1992.

TASSINARI, C. C. G.; MONTALVÃO, R. M.G. Estudo geocronológico do "greenstone belt" de Crixás. In: CONGRESSO BRASILEIRO DE GEOLOGIA, 31., 1980.
Camboriú. Anais... São Paulo, SBG, 1980. p. 2759.

TEIXEIRA, W. The Proterozoic mafic dyke swarms and alkaline intrusions in the Amazonian Craton, South America, and their tectonic evolution based on $\mathrm{Rb}-\mathrm{Sr}$, $\mathrm{K}-\mathrm{Ar}$ and Ar-Ar geochronology. In: PARKER, A. J.; RICKWOOD, P. C.; TUCKER, D. H. (Ed.) Mafic dykes and emplacement mechanisms. Rotterdam: Balkema, 1990. p. 285-296.

TOMAZZOLI, E. R. O greenstone belt de Goiás: estudos geocronológicos. Revista Brasileira de Geociências, São Paulo, v. 22, n. 1, p. 56-60, 1992.

TOMAZZOLI, E. R. Aspectos geológicos e petrológicos do enxame de diques Morro Agudo de Goiás. 1997. Tese (Doutorado) - Instituto de Geociências, Universidade de Brasília, Brasília.

VARGAS, M. C. Geologia das rochas granito-gnáissicas da região de Crixás, Guarinus, Pilar de Goiás e Hidrolina, Goiás. 1992. Dissertação (Mestrado) - Instituto de Geociências, Universidade de Brasília, Brasília.

WAGER, L. R.; BROWN, G. M. Layred igneous rocks. San Francisco: Freeman, 1968. 588p.

WINGE, M. Evolução dos terrenos granulíticos da Província Estrutural Tocantins, Brasil Central. 2000. Tese (Doutorado) - Instituto de Geociências, Universidade de Brasília, Brasília.

WOOD, B. J.; BANNO, S. Garnet-orthopyroxene and orthopyroxene-clinopyroxene relationship in simple and complex system. Contributions to Mineralogy and Petrology, Berlin, v. 42, p. 109-124, 1973.

YODER JR., H. S.; TILLEY, C. E. Origin of basalt magmas: an experimental study of natural and synthetic rock systems. Journal of Petrology, London, v. 3, p. 342-534, 1962. 